Elsevier Editorial System(tm) for Advances in Colloid and Interface Science Manuscript Draft

Manuscript Number: CIS-D-08-00026R1

Title: Design and fabrication of colloidal polymer nanocomposites

Article Type: Special Issue: Brian Vincent

Section/Category:

Keywords: hybrid; nanoparticles; film formation; latex; heteroflocculation

Corresponding Author: Professor Joseph Keddie, PhD

Corresponding Author's Institution: University of Surrey

First Author: Tao Wang, MSc

Order of Authors: Tao Wang, MSc; Joseph Keddie, PhD 


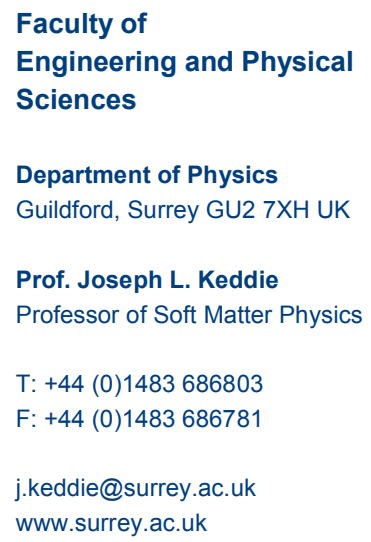

Dear Dr. van Duijneveldt and Professor Starov,

Re: Manuscript CIS-D-08-00026

Thank you for sending us the referees' comments on our manuscript entitled "Design and fabrication of colloidal polymer nanocomposites." We found the comments of the referees to be very helpful, and we have responded as outlined in a separate document (submitted on-line).

Please note that some of our figures are produced in MS office, because we find these figures in their original format have the highest resolution. If the publisher finds think that these figures are not acceptable, please contact us and we will provide the tif format for them. Please also note that the sizes of the figures are not submitted in the final size for the printed page.

We hope that our response to the referees is adequate and that the manuscript is now acceptable for publication. Please contact me if you require anything else.

Sincerely yours,

Professor Joseph Keddie 


\section{Responses to Reviewers' Comments Manuscript CIS-D-08-00026}

\section{Reviewer \#1}

1) It is not explained why 'heat energy' is required for the processing of conventional nanocomposite materials but is not essential for those prepared from polymer colloid systems (p.3).

We have now explained that melt processing usually requires high temperatures to achieve a sufficiently low viscosity, whereas colloids can be processed at temperatures just slightly above the glass transition temperature of the polymer.

2) Where a figure is discussed in the main text (and especially when that work is by another group) the relevant sources should also be referenced within the main text, as well as in the figure caption.

We have now inserted more references within the main text after mentions of the figures.

3) Can an explanation be offered as to why a more densely packed array of particles is favoured when the surface tension of the solution is high, as in the case of vertical deposition? (p.8)

We have now pointed out the importance of the capillary pressure in affecting the particle packing.

4) Figure 8 is mentioned in the text before Figure 7.

The figures have now been re-numbered.

5) "Surprisingly, a minimum value of $\mathrm{N}$ and $<$ rho>a is required for nanoparticles (sic) stabilization by polymer chains, even under good solvent conditions." (p.16) Please explain why this is considered surprising.

On further reflection, we feel that this observation is not surprising, and we have removed the word.

6) "Despite the promise of outstanding mechanical performance, nanocomposites often display mechanical strengths that are far below the idealized theoretical predictions." (p.18) It could be made more clear that this sentence only refers to nanocomposite monoliths (so as to draw comparison with the colloidal nanocomposite examples that follow).

We have now specified that we are referring to the mechanical properties of films and monoliths and not individual particles.

7) In section 4, two distinct routes for the preparation of nanocomposite particles are presented: heteroflocculation and Pickering polymerisation. A third category encompassing the polymerisation of monomer in the presence of a pre-formed inorganic sol should be added, as this is quite distinct from Pickering polymerisation. For example, work by Schmid et 
al. (references 114 and 115) has been cited as examples of Pickering 'armoured' particles, but this is not strictly correct. Although the exact mechanism for the formation of these polystyrene-silica nanocomposite particles is not yet fully understood, it is not the case that the monomer droplets are simply stabilised by the silica sol and subsequent polymerisation results in the formation of 'armoured' particles, because the final particle size (hundreds of $\mathrm{nm}$ ) is significantly smaller than the diameter of the monomer droplets (tens of microns). Thus a subtle distinction should be made between the Pickering emulsion work by Voorn and Bon, and the in situ polymerisation work conducted by both Bourgeat-Lami and co-workers and the Armes group.

We are particularly grateful for this clarification by the referee, and we regret that we did not make a proper distinction between the Pickering emulsion and the in situ polymerisation routes. We have now modified Table 3 to clarify the various methods. We have also added a paragraph to explain the in situ polymerization route. However, because our main focus is on the create of nanostructured composite films and monoliths with desirable properties, we do not want to place more emphasis on the polymerization methods by adding a new section to the manuscript.

8) It should be noted that, in this version of the manuscript, the list of references is somehow incorrect: the numbers above 100 do not have three digits. Is this an 'EndNote' problem?

This problem is attributed to the conversion of the Word document into a pdf file.

\section{Reviewer \#2:}

1. Page 14: The sequence in which the references are discussed in the text should correspond to the sequence in the list of references on pages 29-37. On page 14 [74] appears in the text before [69]. This should be adapted.

The numbering has now been corrected.

2. Page 17: 'After deposition on the substrate, the water will evaporate and the polymer particles will assume a close-packed configuration with the nanotubes occupying interstitial void space'. If I am not mistaken, Jaime Grunlan was one of the first researchers publishing this. It would be appropriate to mention his work here.

Appropriate references have been added, and Grunlan et al. are now mentioned by name.

3. Page 25: 'Figure 14b shows a scheme' instead of 'shows scheme'.

This mistake has been corrected.

4. The item 'Advantages of colloidal nanocomposites' is rather short. I think the authors can think of some additional advantages, e.g. the very efficient way of dispersion/individualisation of nanoparticles (which of course is related to the low percolation thresholds achieved), the low viscosity of the colloidal polymer nanocomposites, which affords easy processing with respect to e.g. melt processing, etc. 
We mentioned advantages in processing in the Introduction, but we have now added further comments at the beginning of Section 6, in line with the referee's recommendation.

5. The numbers in the list of references should be adapted (on page 29 the ' 1 ' is missing in refs. 11-19, on page 32 ref [7] should be [71], on page 34 [00] should be [100] and [01] should be [101], and for [103]-[147] the first ' 1 ' is missing (with a few exceptions).

This problem is attributed to the conversion of the Word document into a pdf file.

6. The quality of some figures is poor, expecially Figs. 6, 7 and 14. Do the authors have high resolution versions?

We have contacted the authors of the cited works, and we have obtained the original figures. 


\title{
Design and fabrication of colloidal polymer nanocomposites
}

\author{
Tao Wang and Joseph L. Keddie \\ Department of Physics and Surrey Materials Institute, University of Surrey, \\ Guildford, Surrey GU2 7XH, United Kingdom
}

Tel: +441483686803

Fax: +44 1483686781

e-mail: j.keddie@surrey.ac.uk

\begin{abstract}
It is well established that colloidal polymer particles can be used to create organised structures by methods of horizontal deposition, vertical deposition, spin-casting, and surface pattern-assisted deposition. Each particle acts as a building block in the structure. This paper reviews how two-phase (or hybrid) polymer colloids can offer an attractive method to create nanocomposites. Structure in the composite can be controlled at the nano-scale by using such particles. Methods to create armored particles, such as via methods of hetero-flocculation and Pickering polymerization, are of particular interest here. Polymer colloids can also be blended with other types of nanoparticles, e.g. nanotubes and clay platelets, to create nanocomposites. Structure can be controlled over length-scales approaching the macroscopic through the assembly of hybrid particles or particle blends via any of the various deposition methods. Colloidal nanocomposites can offer unprecedented long-range $2 \mathrm{D}$ or 3D
\end{abstract}


order that provides a periodic modulation of physical properties. They can also be employed as porous templates for further nanomaterial fabrication. Challenges in the design and control of the macroscopic properties, especially mechanical, are considered. The importance of the internal interfacial structure (e.g. between inorganic and polymer particles) is highlighted.

Keywords: Nanoparticles; hybrids; film formation; heteroflocculation

\section{Contents}



2. Colloidal particle assembly methods ...........................................................

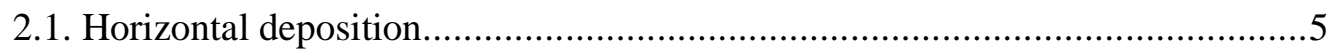

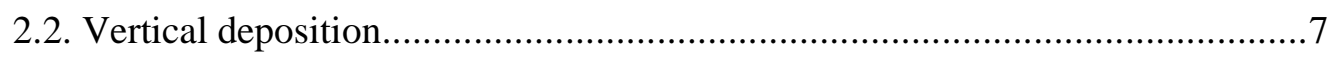





3. Colloidal nanocomposites from particle blends................................................. 13

3.1. Sterically-stabilized suspensions of inorganic nanoparticles....................... 13

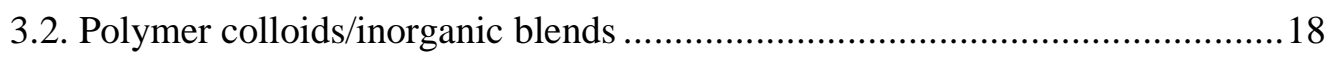

4. Colloidal nanocomposites from colloidal hybrids ..........................................20

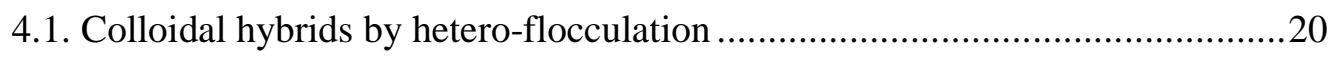

4.2. Polymerisation of hybrid colloidal particles with an inorganic shell ..............21

4.3. Assembly of core-shell hybrid or armored particles to create nanocomposites 23 
5. Interface engineering of colloidal nanocomposites........................................2 24

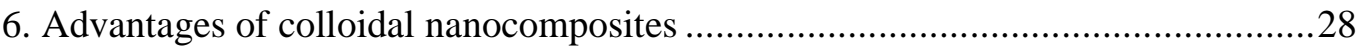

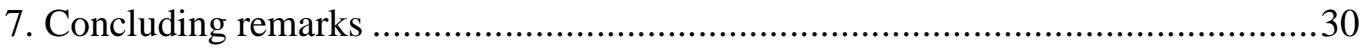

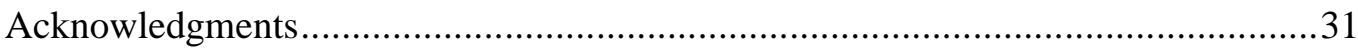

\section{Introduction}

Waterborne polymer colloids, often called latex dispersions, are firmly established for uses in many industrial products, ranging from cosmetics and pharmaceuticals to adhesives and coatings.[1,2] In these applications, single identical homogeneous particles are typically used as the "building blocks" of a larger structure. Particle identity is usually lost upon film formation so that a homogeneous material is created.[3] The science of latex film formation has reached maturity as a result of decades of study.

Within the past decade there has been enhanced interest in using colloidal polymer particles in water to create nanocomposites. There are two broad strategies to make polymer nanocomposites: (1) blends of colloidal polymer particles and a second type of particle (inorganic or polymeric) can be assembled into a desired structure, or (2) hybrid particles consisting of a polymer phase and a second phase can be assembled. Each strategy will be reviewed here. A key advantage of the colloidal approach is that it offers control of structure at the nano-scale (within particles) and at the mesoand even macro-scale through the creation of ordered assemblies of particles. The 
fabrication of nanocomposites offers exciting new challenges and opportunities for the science and technology of latex film formation.

The quest for novel and enhanced properties is a key driver in the development of colloidal nanocomposites. Nanocomposites with nanoscale fillers, e.g. nanoclay [4] and carbon nanotubes [5,6], have pronounced properties that are not realized with traditional micro-scale fillers. The mechanical properties, electrical and thermal conductivity, and flammability resistance all differ in nanocomposites in comparison to conventional composites. Polymer colloids are usually dispersed in water and therefore offer a further attraction over other processing methods. Organic solvents are not emitted into the atmosphere, making the process environmentally-friendly. When the polymer has a glass transition temperature $\left(T_{\mathrm{g}}\right)$ below the ambient conditions, the use of heat energy is not essential for the processing, in stark contrast to the melt-processing fabrication method, which requires lower viscosities and therefore temperatures far above the $T_{\mathrm{g}}$ or the melting temperature. Hence, the waterborne process offers a further environmental benefit.

Our emphasis here will be on hybrid particles in which the core is polymeric and the shell or surface region is inorganic. Hybrid particles with inorganic cores and polymer shells prepared by miniemulsion polymerisation or in-situ polymerisation are not considered, as they have been reviewed elsewhere.[7-9] Polymer/polymer coreshell hybrids are also not considered here.[10] We shall show that latex technology, which was developed in the $1950 \mathrm{~s}$, can be applied and extended to make $21^{\text {st }}$ century materials. The development of colloidal nanocomposites builds on the expertise in 
polymer colloid science developed over several decades. We note, in particular, that the creation of hybrid particles has emerged from the pioneering studies of heteroflocculation by Professor Brian Vincent and his collaborators.

\section{Colloidal particle assembly methods}

We will first consider methods by which waterborne colloidal particles can be assembled to create a desired structure. When a colloidal dispersion of particles in water is deposited onto a substrate and water evaporation is allowed to proceed, either a continuous film or an array of separate isolated particles will form under the appropriate drying conditions. Highly dilute dispersions are used to create isolated particles. The three most common deposition methods for polymer colloids are horizontal deposition [11], vertical deposition [12-14] and spin-casting [15-17]. There is growing interest in the use of surface patterns to assist and guide the particle deposition, and this constitutes a way to control particle deposition by the other three methods. Each of these methods will be considered individually hereafter.

\subsection{Horizontal deposition}

In the horizontal deposition process, the colloidal dispersion is cast on a substrate horizontally such that a planar layer of uniform thickness is created. This flexible and fast method typically creates a layer with a thickness of several microns rather than nanometres. The process is illustrated in Figure 1a, and Figure 1b shows an example of close-packed polymer particles with a 3D-ordered structure obtained by direct horizontal deposition. Such a perfect structure requires a tight control over the 
particle size; polydispersity in size leads to randomness in the packing. The horizontal deposition of glassy colloidal particles to produce colloidal crystals is commonly employed to create templates for the deposition of a second phase. A good example is in the creation of inverse opal structures for photonics applications.[18-20]

Whether or not a continuous film is formed depends on the temperature of the deposition process relative to the minimum film formation temperature (MFFT) of the polymer colloids. In turn, the MFFT is dependent on the viscoelastic resistance of the polymer to deformation. If the film is cast above its MFFT, the film becomes continuous and clear (the average void size is well below the wavelengths of visible light), and the coalescence of the polymer colloid particles can occur. At a temperature below MFFT, a cracked or even powdery film results. Conventionally, the film formation is separated into three primary stages: (I) evaporation of water and particle ordering; (II) particle deformation; and (III) interdiffusion of polymers across the particle-particle boundaries. Mechanisms for particle deformation include dry sintering (driven by the reduction of the polymer/air interfacial energy), wet sintering (driven by the reduction of the polymer/water (serum) interfacial energy), and capillary deformation (driven by the capillary pressure generated across the water/air menisci).[21] A mechanism in which a coalesced surface layer creates osmotic pressure that leads to particle deformation was proposed by Sheetz.[22] Detailed descriptions of the latex film formation process and the drying mechanisms are developed and summarized elsewhere. [23-26] 
Mono-sized particles can be packed into a face-centred cubic array in which each particle has twelve nearest neighbours. When the particles deform to fill all available space, the boundaries between the particles flatten. Each particle then creates a twelve-sided geometric figure known as a rhomboid dodecahedron. If the film is sliced along a (111) plane, a hexagonal array - often called a honeycomb structure is observed.

\subsection{Vertical deposition}

The horizontal deposition of colloidal particles across a large area usually creates a film with defects (e.g. "vacancies") and with lateral variations in the type of packing (e.g. face-centred versus body-centred). On the other hand, vertical deposition has been found to produce superior quality colloidal films with fewer defects and a single packing type. In vertical deposition, a substrate is held vertically in a colloidal dispersion and then lifted away from it to form a well-ordered monolayer or multilayer of particles on the substrate. This method has been modified by dipping the substrate into the dispersion inclined at an angle. Alternatively, the substrate can be dipped into the dispersion and then held in a stationary position while the solvent is allowed to evaporate. The solvent can be allowed to evaporate at either the natural ambient rate or at an accelerated rate to create colloidal layers.[27-30] The vertical deposition is highly effective provided that the evaporation velocity of the solvent exceeds the sedimentation velocity of the particles.[31] 
A schematic diagram of the vertical deposition process is presented in Figure 2a. During vertical deposition, convective mass flow and capillarity are the two main driving forces for the colloids to assemble at the substrate surface [32], with a thickness ranging from several nanometres (corresponding to a particle monolayer) to several microns. Examples of ordered monolayer and seven-layer $(M=7)$ silica microphere films obtained by vertical deposition process are presented in Figures $2 \mathrm{~b}$ and 2c [33], respectively. Vibrations during the lifting or liquid dropping process can detrimentally affect the deposition and packing of the colloidal layers.

The number of particle layers, $M$, in a colloidal film deposited from a dispersion of particles of diameter $\sigma_{c}$ at an initial volume fraction $\varphi$ is controlled by various factors described by the formula [34]

$$
M=\frac{\beta L}{0.605} \frac{j_{e} \varphi}{\sigma_{c} V_{p}(1-\varphi)}
$$

where $\beta$ is a constant varying from 0 to 1 , which depends on particle-particle and particle-substrate interactions, $L$ is the meniscus height (i.e. the width of the wet particle array on the substrate), $j_{e}$ is the evaporation rate of the solvent (water), and $V_{p}$ is the liquid-surface dropping velocity or the lifting speed of the substrate.

The stronger the particle interactions, the smaller is the value of $\beta$.[33] For nonadsorbing particles and dilute suspensions, $\beta$ can be taken as 1 . The evaporation rate is influenced by the temperature and humidity of the surrounding atmosphere. Besides the above parameters, the tilt angle of the substrate when dipped into the colloidal dispersion has been found to affect the thickness of colloidal crystals.[35] An 
investigation of poly(styrene)(PS)-water dispersions [36] demonstrated that $M$ is proportional to the surface tension, but this parameter is not included in Equation 1.

Because of the tendency for sedimentation of larger colloidal particles, there is a limitation to the maximum particle size that can be deposited on a substrate by the vertical method. Both the aqueous phase viscosity and the relative densities of the particles and the water phase affect the sedimentation velocity. Using water as the continuous phase, the maximum colloid size able to be deposited on a substrate is as large as $2 \mu \mathrm{m}$. As can be deduced from Equation 1, the solvent can be chosen to control the colloidal layer thickness. For example, under otherwise identical conditions, the colloidal layers will be thicker when using water rather than ethanol as a solvent, as water has a lower evaporation rate.

The solvent's evaporation rate and surface tension also affect the deposition rate and the packing order.[13,28] For example, when a surfactant is added to decrease the surface tension, a simple cubic array of spaced particles is more favourable, rather than a densely-packed, hexagonal array, which is favoured by a higher surface tension. [28] Particles are drawn together as a result of the negative capillary pressures generated by a concave meniscus in the neck region between particles. This pressure is directly proportional to the surface tension, so that decreasing the surfactant concentration below the critical micelle concentration decreases the extent to which particles are drawn together into a dense array. 


\subsection{Spin-casting}

Whereas horizontal and vertical depositions generally take hours or even days to create colloidal structures, spin-casting methods take only seconds. In this type of processing, the colloidal particles are dispersed in a suitable solvent and then cast onto a rotating substrate, so that shear forces induce two- or three-dimensional film patterns ranging from nanometer to micrometer thicknesses. Figure $3 \mathrm{a}$ shows a scheme of the spin-coating process. An example of a non-close-packed polymer particle array spin-cast on mica is presented in Figure 3b. In the spin-casting process, the evaporation rate of the continuous medium, the spinning velocity, the dispersion concentration, and its viscosity are all key parameters to control the particle packing and thickness of the structure. Unlike horizontal and vertical deposition methods, which usually result in close-packed colloidal particles, spin-casting can fabricate either close-packed [15,16] or isolated [37-40] particle arrays depending on the process conditions.

\subsection{Surface pattern-assisted deposition}

Patterns on the surface of the substrate can be used to control the assembly of colloidal particles. This method has gained considerable attention for reasons of fundamental understanding and for advanced device fabrication.[41-45] Patterns on the substrate can be either chemical or topographical. Particle assembly is achieved by any of the three methods of particle deposition (horizontal, vertical or spin-casting), 
but the surface pattern directs the particles during the process. Spatial confinement leads to the colloidal assembly.

Chemically-patterned surfaces usually have a lateral variation or modulation of electrostatic forces or charges, wettabilities, hydrophilicities, and so on. A scheme of colloidal assembly with chemical patterning is provided in Figure 4a, with an experimental example in Figure 4c [45]. Colloidal particles with a certain surface chemistry will selectively locate on the patterned regions. For instance, electropositive particles will attach to negative regions, or hydrophobic particles will preferentially adsorb onto hydrophobic regions of the substrate.

In topographical patterning, various arrays[46] of holes, grooves or microchannels on substrates are used to guide particle assembly, as illustrated schematically in Figure $4 \mathrm{~b}$ with an experimental example in Figure 4d [46]. Both methods of surface patterning require a sequence of complex manufacturing processes to fabricate the substrate.

Jonas et al. [47] investigated the parameters influencing the templated growth of colloidal particles on chemically-patterned surfaces by vertical deposition. In this case, silanol groups were used to create hydrophilic surface regions, and fluoroalkysilane monolayers were used to create hydrophobic surface patterns. The particles assembled onto the hydrophilic substrate by capillary forces.

Unlike deposition on a non-patterned surface on which the colloid concentration is uniform along the air/solvent/substrate contact line, there is a concentration variation along the contact line when colloids are deposited over a hydrophilic stripe. In 
addition to the usual colloid flux from the bulk of the dispersion to the drying zone, there is a lateral particle flux from the hydrophobic region to the hydrophilic region to counter the discontinuous colloidal concentration. In vertical deposition, the liquid in contact with the hydrophilic stripe rises above the dispersion to a certain height, which is defined as the meniscus length, $L$. The liquid in contact with the hydrophobic stripe sinks below the solution. At the two sides where the hydrophilic and the hydrophobic regions meet, there is an abrupt change of the wettability and consequently a strong deformation of the meniscus shape. When the colloids are deposited on a patterned substrate, the pattern dimensions (line widths) have a strong influence on the deposited layer thickness and colloidal crystal quality.

The deformation of the meniscus and the lateral particle flux makes Eq. 1 no longer valid, especially on substrates with narrow pattern dimensions. For example, a nonlinear dependence of the film thickness on the colloid concentration and the substrate withdrawal speed was identified for line patterns with widths below $100 \mu \mathrm{m}$ in Jonas et al.'s work. [47] Control of this particular deposition behaviour is still based on empiricism and more precise work combined with modelling needs to emerge.

In addition to substrate patterning, electrostatic [48], external electric field [49, 50], floating self-assembly [51], centrifugation [52], filtration [53], and other methods [54-56] have all been investigated as a means for colloidal particle assembly. For example, in Figure $5[51,52]$ there are examples of three-dimensional structure obtained from floating self-assembly and centrifugation, respectively. 


\section{Colloidal nanocomposites from particle blends}

A straightforward way to create nanocomposites is through the blending of polymer particles with inorganic nanoparticles suspended in a common media (either water or an organic solvent). Film formation from particle blends has the potential to fabricate ordered structures that provide a periodic modulation in the optical, photoluminescent, magnetic, electric and mechanical properties, which cannot be otherwise found in homogeneous structures. This method can essentially be considered a nano-scale version of the processing of pigmented latex films, which contain micrometer-sized particles of inorganic oxides, such as titania, silica or calcite. A key challenge is to finely disperse the inorganic nanoparticles in water, and this topic will be considered next.

\subsection{Sterically-stabilized suspensions of inorganic nanoparticles}

Because inorganic nanofillers usually have high surface areas and energies, they tend to aggregate and exhibit poor dispersion ability. Some simple theory explains this effect clearly. The direct interaction force $F_{D}(r)$ between two bare spherical nanoparticles with a particle diameter $\sigma_{c}$ separated at a distance $r$ can be described by an expression for the Lennard-Jones (LJ) potential derived from analytical integration as [57]

$$
F_{D}(r)=\frac{48}{r}\left(\left(\frac{\sigma_{c}}{r}\right)^{12}-\frac{1}{2}\left(\frac{\sigma_{c}}{r}\right)^{6}\right)
$$


The attractive (negative) term with the $r^{-7}$ dependence arises from attractive van der Waals forces. Figure 6a shows the calculated direct LJ force profiles for pairs of particles with various diameters, $\sigma_{c}$. Here, a negative force represents an attraction. The minimum in the force profile becomes lower and moves to a closer separation distance as the nanoparticle diameter decreases. Smaller particles are therefore more prone to aggregate and are more difficult to disperse and stabilize.

To describe the interaction between nanotubes, Girifalco et al. [58] developed an expression for tube-tube interaction from the Lennard-Jones potential. They also derived an expression for tube-sphere interactions to describe nanotubes blended with nanoparticles. Yerushalmi-Rozen and coworkers [59] calculated the interaction potential for two parallel single-wall nanotubes (SWNTs) (expressed per unit length) as a function of the tube-tube distance, $r$, as illustrated in Figure 6b [59]. The attraction is a result of the dispersive energy. Several aspects of Figure $6 \mathrm{~b}$ deserve comment. A negative interaction energy here leads to attraction between the particles. The potential is very short ranged, approaching zero at a distance of about $2.5 \mathrm{~nm}$, which is in contrast to interaction potentials of most colloidal dispersions, which extend much farther. The potential is also quite steep (varying strongly with $r$ ) and the minimum energy level is quite significant, approaching - $40 \mathrm{kT} / \mathrm{nm}$ as $r$ decreases below $2 \mathrm{~nm}$. Considering that carbon nanotubes can be more than $1 \mu \mathrm{m}$ in length, the attractive interaction can be 1000 s of $\mathrm{kT}$. These very high dispersive interaction energies are the origins of the aggregation of nano-objects [60]. In the case of 
nanotubes, the result is the formation of "ropes" or "bundles" and the loss of nanomaterial properties.

To overcome this fundamental problem of aggregation and poor dispersability, inorganic nanoparticles can be decorated with a layer of polymers. These molecules impart steric stability to prevent the nano-inorganics from approaching separation distances in the attractive region.[61] Techniques of steric stabilization have been employed to stabilize various types of colloidal particles, including silica [62], clay [63], gold [64], $\mathrm{Fe}_{3} \mathrm{O}_{4}$ [65] and high aspect-ratio carbon nanotubes, through either covalent bonding[66] of the stabilizer onto the inorganic surface or through physisorption onto the surfaces. Stabilization and dispersion of carbon nanotubes is of particular interest in high-strength nanocomposites, and review articles have been written on the use of surfactants [67] and chemical functionalisation. [68] Note that because of the short-ranged and steep interaction potentials between nanotubes, separating nanotubes by just a few $\mathrm{nm}$ is highly effective in stabilising them in a dispersion $[59,60]$.

As a general rule of thumb, the properties of nanocomposites are usually inferior when the nanophases are not finely dispersed. Aggregates of hard nanoparticles often create a weak point and lead to a loss of optical clarity because of the introduction of heterogeneity in the refractive index at length scales approaching the wavelength of light.[69] Hence, effective methods of dispersing nanoparticles to prevent agglomerates or bundles are essential. 
Figure 7 shows examples of spherical nanoparticles stabilized by chemicallyanchored poly(4-vinylpyridine) [70] and cylindrical multi-wall carbon nanotubes (MWNTs) stabilized by physisorbed poly(vinyl pyrrolidone). To fabricate nanocomposites from waterborne polymer colloids, nano-fillers are usually modified with water-soluble molecules, such as polymers and surfactants, to disperse them in water. To disperse nanoparticles in a hydrocarbon solvent, suitable hydrophobic polymers can be used. Diblock copolymers have been shown to be more effective than homopolymers as dispersants for nanotubes. One block adsorbs on the surface while the other extends into the solvent to impart steric stability [61].

Lessons for the steric stabilisation of nanoparticles can be learned from the theory describing the interactions between polymer brushes on flat surfaces developed by Alexander[71], de Gennes[72] and Milner et al.[73] The steric interaction force, $F(r)$, between polymer brush layers of thickness $\delta$, separated by a distance $r$, was proposed by de Gennes[74] to be

$$
F(r)=\frac{\alpha k T}{s^{3}} \times\left[\left(\frac{2 \delta}{r}\right)^{\frac{9}{4}}-\left(\frac{r}{2 \delta}\right)^{\frac{3}{4}}\right] .
$$

Here, $k$ is the Boltzmann constant, $T$ is the absolute temperature, $s$ is the distance between the terminally-attached polymer chains, and $\alpha$ is a fitting parameter.

End-anchored polymers on nanoparticles can be treated - to a first approximation as polymer brushes. On a flat surface, the volume available per grafted chain is constant as a function of the distance from a planar grafting surface, whereas the available volume increases with distance for a polymer brush on a highly curved 
surface. This will affect the extent of confinement on the brushes. The ability to design polymer modifiers on a nano-surface allows precise control of the colloidal suspension for nanocomposite fabrication and will influence the structure and property modulation, through its effect on dispersability and flocculation.

Simulations of the interaction force between freely-absorbing polymers on spherical nanoparticles [57] and between end-tethered polymers on both nanoparticles [75] and on cylindrical carbon nanotubes [61] have been developed. The nanoparticle interaction forces due to the adsorbed polymers, $F_{P}(r)$, on nanoparticles have been simulated by an expanded grand canonical Monte Carlo simulation method for systems in which the stabilising polymer is similar in size to the nanoparticle. $[57,75]$

This simulation evaluates the effect of $\sigma_{c}$, polymer chain length $(N)$, grafting density $\left(\rho_{\mathrm{a}}\right)$, and colloid-polymer and polymer-polymer interaction energies on the polymer-induced force profiles between nanoparticles. The total binary nanoparticle interaction force is the sum of the two types of force: $F(r)=F_{P}(r)+F_{D}(r)$. The total force between nanoparticles is illustrated in Figure 8a [75]. As expected, there is a repulsion from steric interactions between the grafted chains. However, there is also an attraction from polymer chains bridging two particles and from polymer segmentsegment interactions. In the competition, the repulsion prevents close approach in comparison to bare particles, but it is often insufficient to overcome the attraction entirely. These simulations show that tethered polymers are not particularly effective for dispersing very small nanoparticles. 
A minimum value of $N$ and $\rho_{\mathrm{a}}$ is required for nanoparticle stabilization by polymer chains, even under good solvent conditions. Beyond the minimum $N$ and $\rho_{\mathrm{a}}$, excluded volume effects begin to dominate over the attractive forces, leading to purely repulsive forces and hence the stabilization of the nanoparticles. On the other hand, short chains or low grafting densities are ineffective in providing nanoparticle stabilisation. The effects of end-tethered polymer chains around carbon nanotubes have also been simulated by self-consistent mean field methods. Similarly, a steric repulsion is provided by the polymer layer. In this case, the repulsion prevents the nanotubes from moving close together into the attractive regime. The repulsive energy barrier, presented in Figure $8 \mathrm{~b}$ as a positive energy, increases with increasing chain length and prevents nanotube contact.[60] According to the simulation, with sufficiently long polymer chains, the total interaction energy is entirely repulsive.

After the film formation of a colloidal nanocomposite, the polymer dispersant on a nanoparticle will come into contact with the continuous polymer matrix. The interaction with this polymer chain and the matrix is expected to have a profound effect on properties. The dispersant can be used to promote adhesion between the filler and the matrix. Recent relevant results will be considered in Section 5.

\subsection{Polymer colloids/inorganic blends}

Provided that they can coexist in a common media (e.g. water), polymer colloids can be blended with spherical nanoparticles or high aspect-ratio nano-clay platelets or nanotubes. An ordered, nanostructured nanocomposite can be created via horizontal 
or vertical deposition. Taking nanotubes as an example, a nanocomposite is created by blending finely-dispersed nanotubes and colloidal polymer particles uniformly in water. After deposition on the substrate, the water will evaporate and the polymer particles will assume a close-packed configuration with the nanotubes occupying interstitial void space.[76, 77] Finally, the polymer particles will coalesce to form a coherent film, locking the SWNTs within a so-called segregated network [77]. This method was first demonstrated by Grunlan et al. and has been used increasingly more often by others. Figure $9 \mathrm{a}$ demonstrates an ordered honeycomb structure achieved from casting a binary blend of a polymer colloids and carbon nanotubes.

Despite the promise of outstanding mechanical performance, nanocomposite films and bulk materials often display mechanical strengths that are far below the idealized theoretical predictions. This failure has been attributed to poor nanofiller dispersion in the polymer matrix and to weak interfacial adhesion with the matrix, as well as the random and uncontrolled morphology of the nanocomposites. [78,79] Polymer nanocomposites by colloidal routes have the potential to resolve these problems by achieving uniform mixing at the colloidal length scale.

In this type of nanocomposite, the nanostructures are controlled through the polymer colloid particle size and the relative volume fractions in the blends. Besides polymer colloids, inorganic colloids, such as silica particles in water, can also be used in this process. Figure $9 \mathrm{~b}$ gives an example of a carbon nanotube network created by using silica as a colloidal template, fabricated by vertical deposition.[80] Figure 9c shows a PS-silica nanocomposite achieved with accelerated vertical deposition.[13] 
Table 1 summarizes the ordered colloidal nanocomposites deposited from various colloidal blends, which have been reported in the literature recently.

\section{Colloidal nanocomposites from colloidal hybrids}

In another approach, two-phase or hybrid particles - rather than homogeneous particles - are used as the basic building blocks for a nanocomposite. In polymer hybrid particles, the second phase can be either another polymer or an inorganic nanoparticle. The two primary methods for creating colloidal hybrid particles will be reviewed next.

\subsection{Colloidal hybrids by hetero-flocculation}

In one approach for creating hybrid particles, a polymer particle can be used as a nano-scale substrate surface onto which inorganic nano-objects are attached through a hetero-flocculation process. One of the first examples of the hetero-flocculation of smaller particles on larger particles was reported by Vincent and collaborators.[89] They used careful control of the charge to cause the adsorption of small colloidal particles onto larger, oppositely-charged colloidal particles. Since this pioneering work, others have gone on to attach inorganic nanoparticles, nanotubes, or clay platelets onto larger colloidal polymer spheres. The hetero-flocculation process can be driven by solvent treatment [90], $\mathrm{pH}$ adjustment [91], ion exchange [92], opposite charges [93], hydrogen bonding, or specific chemical reactions [94]. When the charge or polarity of colloid surfaces is used to attract nanocrystals, the process is usually referred to as controlled precipitation. In the case of precipitation on polymer 
colloids, the surface needs to be decorated with a layer containing $-\mathrm{NH}_{2},-\mathrm{COOH}$, $\mathrm{SO}_{4} \mathrm{H},-\mathrm{SO}_{3} \mathrm{H},-\mathrm{OH},-\mathrm{SH},-\mathrm{CONH}_{2},-\mathrm{CH}_{2} \mathrm{NH}_{2},-\mathrm{CH}_{2} \mathrm{Cl}$ or similar groups. [95]

When the hetero-flocculation occurs, a core-shell particle is created, in which a polymer core is surrounded by an inorganic shell. The thickness of the shell can be effectively controlled through the concentration ratio of the polymer colloids and the attached inorganic nanoparticles. Figure 10 schematically illustrates the assembly of various inorganics, e.g. 3-D nanoparticles, 2-D nanoclays and 1-D nanotubes, onto polymer colloid surfaces. Numerous types of inorganics, with nano-scale or microscale dimensions, have been attached onto polymer colloids to create colloidal hybrid particles, as summarized in Table 2. Figure 11 gives an example of carbon nanotubes deposited on polystyrene particle surfaces. [91] In some cases, the inorganic shell layer is referred to as "armour" to emphasize its hardness in comparison to the polymer core.

\subsection{Polymerisation of hybrid colloidal particles with an inorganic shell}

A new emerging alternative method to create colloidal hybrids is by Pickering polymerization. The tendency for solid particles to adsorb strongly at liquid-liquid interfaces was first described by Ramsden [106] and Pickering [107] in the early 1900s. This phenomenon is known as Pickering stabilization, and it is used widely to stabilize emulsions in a variety of applications, e.g. foods, cosmetics, paper-making, paints, and crude-oil recovery.[108,109] The general mechanisms of emulsion stabilization by solid particles have been attributed to both the creation of coherent 
particle layers and the formation of particle bridges when the droplets are sparsely covered.[110] The liquid-liquid interface can be used as a template to capture particles and to guide their assembly to create a variety of complex supracolloidal structures, referred to as Pickering emulsions.

To create hybrid polymer particles, monomers can be emulsified in water using inorganic nanoparticles as the stabilizer. Then, emulsion polymerization $[111,112]$ can be carried out to prepare polymeric nanocomposite particles, as presented schematically in Figure 12a. SEM images of laponite clay-armored polystyrene latex particles and montmorillonite clay-armored polyacrylamide latex particles are shown as further examples in Figures 12b [111] and 12c [113], respectively.

There is also extensive work by the Armes group on colloidal hybrids by dispersion or emulsion polymerization of monomers in the presence of a pre-formed inorganic sol. [114-116] They have prepared numerous types of colloidal hybrid structures, including raspberry, currant bun, silica-core/polymer-shell and polymercore/silica-shell structures. As one particular example of interest here, they have synthesized poly(2-vinylpyridine)-silica [114] and polystyrene-silica colloidal hybrids $[115,116]$ with the polymer in the cores and silica in the shells, as determined by XPS and by elemental distribution analysis. The selection of the initiator is the key to the formation of colloidally-stable nanocomposite particles. The exact mechanism for the formation of these hybrids with silica as shells is not yet fully understood. It is not the case that the monomer droplets are simply stabilised by the silica sol and the subsequent polymerisation forms the "armoured" particles, because the final particle 
size (hundreds of $\mathrm{nm}$ ) is significantly smaller than the diameter of the monomer droplets (tens of $\mu \mathrm{ms}$ ).

Yet another method to prepare polymer particles with inorganic "armour" is via in-situ polymerization. Bourgeat-Lami et al. have used organically-modified laponite clay as seeds for emulsion polymerization and thereby prepared various colloidal hybrids with clays located at the polymer particle surfaces [117-119]. The processing conditions affected the particle morphology and latex stability. Table 3 summarizes various armoured hybrid particles by these various polymerization methods. The list is not exhaustive but is meant to provide examples.

\subsection{Assembly of core-shell hybrid or armored particles to create nanocomposites}

Polymer hybrid particles, created by the deposition methods just described, can be assembled to form nanocomposites with a structure ordered at the nanoscale.[125] The hybrid particles are most often packed on a face-centered cubic lattice [12,52], but body-centered cubic, body-centered orthorhombic, space-filling tetragonal, bodycentered tetragonal lattices are also possible.[32] After the deposition process, an ordered structure can be found, with inorganic particles (e.g. nanoclay or nanotubes) situated at the boundaries between the colloidal polymer particles. If the temperature of the deposition process is less than the polymer $T_{\mathrm{g}}$, the polymer particles will remain spherical. At higher deposition and processing temperatures, the particles will deform to fill all available space, thus creating a honey-comb structure with the inorganic phase comprising the walls. In the case of a hard polymer (with a $T_{\mathrm{g}}$ above the 
deposition temperature), the particles create a template on which the inorganic phase is arranged. Figure 13a is an example of an ordered honeycomb structure obtained from poly(styrene-co-butyl acrylate) $(\mathrm{P}(\mathrm{St}-\mathrm{co}-\mathrm{BuA}) /$ clay hybrid particles prepared by Pickering emulsion polymerization.[119] An example of using polymer colloids as a template is shown in Figure 13b [101]. In this case, surface hetero-flocculation was used to encapsulate PS particles with single-wall carbon nanotubes. An ordered network of nanotubes was created in the deposition process. Thereafter, the polymer was etched away to leave behind the templated nanotube network structure.

The ordered nanocomposite structure can be adjusted through $\sigma_{\mathrm{c}}$ (varying from tens of nanometers to a few microns), the polydispersity of the size, the chemical architectures in the polymer core, the composition of the armored shell, and the shell thickness, $l_{\mathrm{s}}$. When using colloidal hybrids to produce 3-D polymer nanocomposites, $\sigma_{c}$ and $l_{s}$ can be tailored during the emulsion polymerization process or the heteroflocculation process to adjust the core particle density in the final nanocomposite.

\section{Interface engineering of colloidal nanocomposites}

Driving the development of these nanocomposites is the fact that, when properly designed, they have desirable combinations of properties that are not found in the individual components. As one example, when $\mathrm{P}(\mathrm{St}-\mathrm{co}-\mathrm{BuA}) /$ clay hybrid particles are assembled into a nanocomposite, a percolating network of clay platelets is created. [119] This network is quite efficient in mechanical reinforcement, giving a 50-fold 
increase in the Young's modulus in comparison with the polymer alone. There is also a strong increase in the maximum stress before failure and in the toughness. Another example is nanocomposite adhesives from soft polymer colloids and carbon nanotubes. [84] The carbon nanotubes are used to tune the viscoelastic properties (elastic modulus and energy dissipation rate) of the nanocomposites and enhance the pressure-sensitive adhesive properties.

Colloidal methods of nanocomposite processing use building blocks with a very high surface area, which results in nanocomposites with an extremely high internal interfacial area. For instance, the interfacial area between particles with a radius of $125 \mathrm{~nm}$ (assuming particle deformation but not coalescence) is greater than $10 \mathrm{~m}^{2}$ for every gram of polymer. It is perhaps no surprise therefore to find from recent research that the composition and properties of the molecules at the interfaces between particles have a profound effect on the mechanical properties of the nanocomposite. In the case of colloidal nanocomposites, Wang et al. [85] have pointed out that the dispersant for waterborne nanoparticles becomes localised at the interface with the matrix. It was found that the value of the adhesive criterion, tan $\delta / \mathrm{E}$, of the poly(buty acrylate) $\mathrm{P}(\mathrm{BuA}) / \mathrm{MWNT}$ colloidal nanocomposites can be tuned through control of the interfacial structure. A small molecule (surfactant) or short chain polymer yielded inferior an $\tan \delta / \mathrm{E}^{\prime}$ value compared to high molecular polymer chains at the nanotube/matrix interface, and consequently a lower adhesion energy resulted. Figure 14a illustrates the correlation of the colloidal nanocomposite's adhesion energy with $\tan \delta / \mathrm{E}^{\prime}$. The adhesion energies of the nanocomposite 
adhesives can be adjusted by the extent of chain entanglement and molecular friction at the interface between the filler and the matrix.

Fundamentally, the performance and fracture mechanism of polymer nanocomposites containing high aspect-ratio fillers (e.g. nano-fibers [126], carbon nanotubes [127], and nano-platelets [128]) are controlled by the interfacial strength between the matrix and the filler and by the filler's aspect ratio. A nano-filler will break during deformation of the nanocomposite only when the stress transferred to it is larger than its fracture strength. If the transferred stress does not exceed the filler's fracture strength, the filler will pull out from the matrix. The critical length, $L_{\mathrm{c}}$, defined as the minimum length at which the stress transferred to a nano-filler equals its fracture strength, is calculated for fibers and platelets as

$$
L_{c}=\frac{\sigma_{f} D}{2 \tau}
$$

where $\sigma_{\mathrm{f}}$ is the filler fracture strength, $D$ the filler diameter, and $\tau$ the interfacial strength. The critical length of carbon nanotubes is calculated as

$$
L_{c}=\frac{\sigma_{f} D}{2 \tau}\left[1-\frac{D_{i}{ }^{2}}{D^{2}}\right]
$$

with $D_{i}$ being the inner diameter of the nanotubes. The nano-filler will pull-out from the matrix when its length $L_{\mathrm{NF}}$ is less than $L_{\mathrm{c}}$, and it will fracture when $L_{\mathrm{NF}}>L_{\mathrm{c}}$. It is expected that the fracture of most colloidal nanocomposites will occur by nano-filler pull-out, because of the difficulty in achieving a high $\tau$.

In order for a nano-filler to increase the strength of a nanocomposite, clearly stress must be transferred from the matrix. Recent work has used covalent bonding of the 
matrix to the filler to ensure a high interfacial strength. [129] There are various examples in the literature showing that an increase in $\tau$ leads to increased macro-scale strength and toughness. For instance, spherical nanoparticles in PP or PS systems [130] are highly effective in toughening the nanocomposite when the testing temperature is above the glass transition temperature $\left(T_{g}\right)$ of the polymer matrix. At the higher temperatures, the polymer can wet the nano-fillers and provide good interfacial adhesion. A second example of interfacial effects is that when a polymer is grafted onto MWNTs to improve miscibility with the matrix, the efficient load transfer from the matrix to the nanotubes increases the mechanical performance. [131] Yet another example is that a high density of grafted polymer chains on SWNT surfaces leads to more effective interfacial stress transfer and results in a pronounced mechanical reinforcement. [132]

Inspired by previous studies of how polymer chain length $(N)$ and density $(\Sigma)$ at interfaces influence fracture [133-135], adhesion [136], and friction [137,138], Wang et al. [139] systematically investigated the interfacial control of $\tau$ in a soft polymernanotube nanocomposite through the chain length and density of the polymers physisorbed on carbon nanotube surfaces and then located at the nanocomposite interfaces. Figure $14 \mathrm{~b}$ shows a scheme of physisorbed polymers on the carbon nanotube surface. The results showed that $\tau$ increases with $\Sigma$ but then levels off above a critical value. The value of $\tau$ (per chain) increases with increasing chain length. They explained their results through an analogy between the force required in the nanotube pull-out process and the friction force of polymer brushes on solid surfaces 
sliding along a rubber. They predicted that the monomeric friction coefficient of different polymers could be used to tune the interfacial strength and consequently to adjust the macroscopic properties of colloidal nanocomposites.

\section{Advantages of colloidal nanocomposites}

As mentioned in the Introduction, colloidal nanocomposites are fabricated through blending of particles at the nanoscale in the aqueous phase. The processing temperature only needs to be slightly higher than the glass transition temperature of the polymer. In comparison to colloidal dispersions, polymer melts have much higher viscosities, so that blending with inorganic phases is much less efficient. It is not easy to disperse individual inorganic nanopoarticles in the viscous melt. Lower melt viscosities are only obtained at temperatures well-above the polymer $T_{\mathrm{g}}$, and nevertheless, inorganic particle agglomeration can still be problematic.

Colloidal nanocomposites are more efficient for mechanical reinforcement, because of the uniform dispersion of the inorganic phase and the 3-D periodically ordered structure. Examples of mechanical improvement and influences controlling the mechanical properties have been discussed in Section 5. As a general rule, low percolation thresholds require particles that are randomly oriented, finely-dispersed (not agglomerated or bundled), and having a high aspect ratio. The colloidal route can satisfy all of these requirements.

The 3-D percolating network of a conducting inorganic phase can impart high electrical conductivity, and so measurements of conductivity are a good probe of the 
structure. For instance, a three-dimensional honeycomb network of SWNTs created around PS colloidal particles has an electrical conductivity on the order of $10^{4}$ $\mathrm{Sm}^{-1}$.[101] The percolation threshold for the onset of electrical conductivity in a nanocomposite of colloidal poly(vinyl acetate) latex and SWNTs has been found to be as low as $0.04 \mathrm{wt} \%$.[82] By comparison, larger filler particles, i.e. micrometer-sized carbon black particles, have a percolation threshold of 2 vol.\% in blends with a polymer colloid.[86] A percolating network of a conducting polymer in a colloidal nanocomposite achieved a percolation threshold of 0.011 , which is a factor of 10 lower than in a conventional blend, accompanied by an electrical conductivity that is several orders of magnitude greater.[140] Elsewhere, a soft colloidal nanocomposite of $\mathrm{P}(\mathrm{BuA})$ and SWNTs achieved a percolation threshold of only $0.03 \mathrm{wt} \%$.[84] These colloidal nanocomposites can serve as electrically-conductive adhesives and coatings and find applications in electronic devices and displays.

There is also interest in using the assembly of colloidal particles to template inorganic phases in a structure ordered on the nano-scale. The polymer cores in hybrid colloidal particles can be removed by chemical etching or calcination. A porous inorganic structure is left behind, and this inverse opal structure can serve as a template for other nanomaterials or 3D scaffolds for cell or tissue engineering. [51, $141-143]$

Most existing cell and tissue scaffolds have the drawbacks of having a poorly ordered or even chaotic structure, requiring a complex fabrication process, and using a limited materials selection. The 3D scaffolds fabricated from colloidal nanocomposite 
networks allow the facile design of porosity, interconnectivity and pore size. The biocompatibility of the inorganic scaffolds can be modified by chemically-selected polymer layers on the inorganic surface. These mechanically strong, biocompatible and well-connected inverse opal structures mimic very well the micro-environment of three-dimensionally organized native tissues, providing the potential to systematically study cell growth as well as cell-cell and cell-matrix interactions.

Colloidal nanocomposites with structures tailored on the nano-scale also have applications in printed flexible electronics [144], photonic bandgaps [145,146], sensors [147], data storage [148], and displays [149]. Of course, one of the oldest applications of waterborne polymer colloids is for architectural coatings. Colloidal nanocomposites of polyacrylates and silica have been developed by BASF [150] for commercial applications as a transparent, flame-retardant, scratch-resistant coating. [151].

\section{Concluding remarks}

This review has shown how recent research has drawn upon basic latex technology in the development of a class of nanocomposites. The use of hybrid particles provides control at the nano-scale, whereas the arrangement of particles into colloidal crystal arrays offers controlled periodicity and symmetry at the mesoscale. The properties of colloidal nanocomposites are modulated over these length scales.

In comparison to nanocomposites made by processing of polymer melts or solutions, colloidal nanocomposites exhibit desirable properties as a direct result of 
their structure. For instance, the percolation threshold for electrical conductivity tends to be lower in colloidal nanocomposites. Furthermore, when rigid particles are structured around deformable polymer particles, the former impart stiffness whereas the latter impart high strains at failure and toughness. Soft nanocomposites made by the colloidal route hold particular promise.

To date, most of the emphasis in the literature has been on making hybrid materials and ordered structures, but there has been far less emphasis on the relationship between the nano/mesostructure and properties. In order for colloidal nanocomposites to be developed for demanding applications, greater effort must be made in this direction. Recent results have proven the key role that internal interfaces between nano-phases can play in determining properties, especially mechanical. Interfacial design therefore is expected to be a particularly worthwhile pursuit.

\section{Acknowledgments}

TW acknowledges an Overseas Research Student Scholarship from Universities UK and a University Research Scholarship from the University of Surrey. JLK acknowledges many useful conversations with Prof. C. Creton (ESPCI), Prof. J.M. Asua (University of the Basque Country), Dr. A.B. Dalton (University of Surrey), and many partners within the EC FP6 project, NAPOLEON (contract IP 011844-2). We dedicate this paper to Professor Brian Vincent who has inspired, guided and nurtured several generations of polymer colloid scientists.

\section{References}


[1] Fitch RM. Polymer Colloids: A Comprehensive Introduction. Academic Press; New York, 1997.

[2] Nelson EC, Braun PV. Science 2007; 318: 924.

[3] Joanicot M, Wong K, Cabane B. Macromolecules 1996; 29: 4976.

[4] Giannelis EP. Adv Mater 1996; 8: 29.

[5] Ajayan PM, Tour JM. Nature 2007 ; 447: 1066.

[6] Coleman JN, Khan U, Gun'ko YK. Adv Mater 2006; 18: 689.

[7] Asua JM. Prog Polym Sci 2002; 27: 1283.

[8] Advincula RC. J Disper Sci Technol 2003; 24: 343.

[9] Bourgeat-Lami E. J Nanosci Nanotech 2002; 2: 1.

[10] Guyut A, Landfester K, Schork FJ, Wang CP. Prog Polym Sci 2007; 32: 1439.

[11] Zeng F, Sun ZW, Wang CY, Ren BY, Liu XX, Tong Z. Langmuir 2002; 18: 9116.

[12] Wang JJ, Ahl S, Li Q, Kreiter M, Neumann T, Burkert K, Knoll W, Jonas U. J Mater Chem 2008; 18: 981.

[13] Kitaev V, Ozin GA. Adv Mater 2003; 15: 75.

[14] Wang LK, Zhao XS. J Phys Chem C 2007; 111: 8538.

[15] Wang DY, Möhwald H. Adv Mater 2004; 16: 244.

[16] Mihi A, Ocana M, Miguez H. Adv Mater 2006; 18: 2244.

[17] Jiang P, McFarland MJ. J Am Chem Soc 2004; 126: 13778.

[18] Stein A, Schroden RC. Curr Opin Solid St M 2001; 5: 553.

[19] Shimmin RG, Vajtai R, Siegel RW, Braun PV. Chem Mater 2007; 19: 2102. 
[20] Stein A, Li F, Denny NR. Chem Mater 2008; 20: 649.

[21] Routh AF, Russel WB. Langmuir 1999; 15: 7762.

[22] Sheetz DP. J Appl Polym Sci 1965; 9: 3759.

[23] Chevalier Y, Pichot C, Graillat C, Joanicot M, Wong K, Maquet J, Lindner P, Cabane B. Colloid Polym Sci 1992; 270: 806.

[24] Keddie JL. Mater Sci Eng 1997; 21: 101.

[25] Steward PA, Hearn J, Wilkinson MC. Adv Colloid Interface 2000; 86: 195.

[26] Zhou ZC, Li Q, Zhao XS. Langmuir 2006; 22: 3692.

[27] Jiang P, Bertone JF, Hwang KS, Colvin VL. Chem Mater 1999; 11: 2132.

[28] Cong HL, Cao WX. Langmuir 2003; 19: 8177.

[29] Zhou Z, Zhao XS. Langmuir 2004; 20: 1524.

[30] Cong HL, Cao WX. J Phys Chem B 2005; 109: 1695.

[31] Shimmin RG, DiMauro AJ, Braun PV. Langmuir 2006; 22: 6507.

[32] Dziomkina NV, Vancso GJ. Soft Matt 2005; 1: 265.

[33] Li JA, Han YC. Langmuir 2006; 22: 1885.

[34] Dimitrov AS, Nagayama K. Langmuir 1996; 12: 1303.

[35] Im SH, Kim MH, Park OO. Chem Mater 2003; 15: 1797.

[36] Zhou ZC, Zhao XS. Langmuir 2005; 21: 4717.

[37] Venkatesh S, Jiang P, Jiang B. Langmuir 2007; 23: 8231.

[38] Jiang P, McFarland MJ. J Am Chem Soc 2005; 127: 3710.

[39] Jiang P. Langmuir 2006; 22: 3955.

[40] Sun CH, Linn NC, Jiang P. Chem Mater 2007; 19: 4551. 
[41] Lee W, Chan A, Bevan MA, Lewis JA, Braun PV. Langmuir 2004; $20: 5262$.

[42] Schaak RE, Cable RE, Leonard BM, Norris BC. Langmuir 2004; 20: 7293.

[43] Masuda Y, Itoh T, Itoh M, Koumoto K. Langmuir 2004; 20: 5588.

[44] Ren ZY, Li X, Zhang JH, Li W, Zhang XM, Yang B. Langmuir 2007; 23: 8272.

[45] Chen KM, Jiang X, Kimerling LC, Hammond PT. Langmuir 2000; 16: 7825.

[46] Xia YN, Yin YD, Lu Y, Mclellan J. Adv Fun Mater 2003; 13:907.

[47] Fustin CA, Glasser G, Spiess HW, Jonas U. Langmuir 2004; 20:9114.

[48] Aizenberg J, Braun PV, Wiltzius P. Phys Rev Lett 2000; 84: 2997.

[49] Zhang KQ, Liu XY. Nature 2004; 429: 739.

[50] Hayward RC, Saville DA, Aksay IA. Nature 2000; 404: 56.

[51] Liu YF, Wang SP, Lee JW, Kotov NA. Chem Mater 2005; 17: 4918.

[52] Deng YH, Liu C, Liu J, Zhang F, Yu T, Zhang FQ, Gu D, Zhao DY. J Mater Chem 2008; 18: 408.

[53] Hoa MLK, Lu MH, Zhang Y. Adv Colloid Interface Sci 2006; 121: 9.

[54] Prevo BG, Velev OD. Langmuir 2004; 20: 2099

[55] Pan F, Zhang JY, Cai C, Wang TM. Langmuir 2006; 22: 7101.

[56] Malaquin L, Kraus T, Schmid H, Delamarche E, Wolf H. Langmuir 2007; 23: 11513.

[57] Marla KT, Meredith JC. Langmuir 2005; 21:487.

[58] Girifalco LA, Hodak M, Lee RS. Phys Rev B 2000; 62: 13104.

[59] Shvartzman-Cohen R, Nativ-Roth E, Baskaran E, Levi-Kalisman Y, Szleifer I, Yerushalmi-Rozen R. J Am Chem Soc 2004; 126:14850. 
[60] Yerushalmi-Rozen R, Szleifer I. Soft Matt. 2006; 2: 24.

[61] Shvartzman-Cohen R, Levi-Kalisman Y, Nativ-Roth E, Yerushalmi-Rozen R. Langmuir 2004; 20: 6085.

[62] Li, DJ, Sheng X, Zhao B. J Am Chem Soc 2005; 127: 6248.

[63] Shah D, Fytas G, Vlassopoulos D, Di J, Sogah D, Giannelis EP. Langmuir 2005;

21: 19 .

[64] Ohno K, Koh K, Tsujii Y, Fukuda T. Macromolecules 2002; 35: 8989.

[65] Lattuada M, Hatton TA. Langmuir 2007; 23: 2158.

[66] Pyun J, Matyjaszewski K. Chem Mater 2001; 13: 3436.

[67] Vaisman L, Wagner HD, Marom G. Adv Colloid Interface Sci 2006; 128-130:

37.

[68] Lin Y, Meziani MJ, Sun Y-P. J Mater Chem. 2007; 17: 1143.

[69] Vandervorst, P, Lei C, Lin Y, Dupont O, Dalton AB, Sun Y-P, and Keddie JL. Prog Organic Coat 2006; 57: 91.

[70] Li DX, He Q, Cui Y, Li JB. Chem Mater 2007; 19: 412.

[71] Alexander SJ. J Phys (Paris) 1977; 38: 977.

[72] de Gennes PG. Macromolecules 1980; 13: 1069.

[73] Milner ST. Science 1991; 251: 905.

[74] de Gennes PG. Adv Colloid Interface Sci 1987; 27: 189.

[75] Marla KT, Meredith JC. J Chem Theory Comput 2006; 2: 1624.

[76] Grunlan JC, Mehrabi AR, Bannon MV, Bahr JL. Adv Mater 2004; 16: 150. 
[77] Grunlan JC, Kim Y-S, Ziaee S, Wei X, Abdel-Magid B, Tao K. Macro Mater Eng 2006; 291: 1035.

[78] Moniruzzaman M, Winey KI. Macromolecules 2006; 39: 5194.

[79] Vaia RA, Maguire JF. Chem Mater 2007; 19: 2736.

[80] Kim MH, Choi J-Y, Choi HK, Yoon S-M, Park OO, Yi DK, Choi SJ, Shin H-J. Adv Mater 2008; 20: 457.

[81] Dufresne A, Paillet M, Putaux JL, Canet R, Carmona F, Delhaes P, Cui S. J Mater Sci 2002; 37: 3915.

[82] Regev O, El Kati PNB, Loos J, Koning CE. Adv Mater 2004; 16: 248.

[83] Grossiord NG, Loos J, Koning CE. J Mater Chem 2005; 15: 2349.

[84] Wang T, Lei CH, Dalton AB, Creton C, Lin Y, Fernando KAS, Sun Y-P, Manea M, Asua JM, Keddie JL. Adv Mater 2006; 18: 2730.

[85] Wang T, Lei CH, Liu D, Manea M, Asua JM, Creton C, Dalton AB, Keddie JL. Adv Mater 2008; 20: 90.

[86] Grunlan JC, Gerberich WW, Francis LF. Polym Eng. Sci.2001; 41: 1947.

[87] Tessier PM, Velev OD, Kalambur AT, Lenhoff AM, Robolt JF, Kaler EW. Adv Mater 2001; 13: 396.

[88] Tessier PM, Velev OD, Kalambur AT, Robolt JF, Lenhoff AM, Kaler EW. J Am Chem Soc 2000; 122: 9554.

[89] Harley S, Thompson DW, Vincent B. Colloid Surface 1992; 62: 163.

[90] Radtchenko IL, Sukhorukov GB, Gaponik N, Kornowski A, Rogach AL, Mohwald H. Adv Mater 2001; 13: 1684. 
[91] Paunov VN, Panhuis MIH. Nanotechnology 2005; 16: 1522.

[92] Rossi GB, Beaucage G, Dang TD, Vaia RA. Nano Lett 2002; 2: 319.

[93] Caruso F, Susha AS, Giersig M, Möhwald H. Adv Mater 1999; 11: 950.

[94] Mayer ABR, Grebner W, Wannemacher R. J Phys Chem B 2000; 104: 7278.

[95] Xia YN, Gates B, Yin YD, Lu Y. Adv Mater 2000; 12: 693.

[96] Caruso RA, Susha A, Caruso F. Chem Mater 2001; 13: 400.

[97] Tian CG, Mao BD, Wang EB, Kang ZH, Song YL, Wang CL, Li SH. J Phys Chem C 2007; $111: 3651$.

[98] Khan MA, Perruchot C, Armes SP, Randall DP. J Mater Chem 2001; 11: 2363

[99] Pich A, Hain J, Prots Y, Adler HJ. Polymer 2005; 46: 7931.

[100] Sherman RL, Ford WT. Langmuir 2005; 21: 5218.

[101] Dionigi C, Stoliar P, Ruani G, Quiroga SD, Facchini M, Biscarini F. J Mater Chem 2007; 17: 3681.

[102] Susha AS, Caruso F, Rogach1 AL, Sukhorukov GB, Kornowski A, Möhwald H, Giersig M, Eychmüller A, Weller H. Colloid Surface A 2000; 163: 39.

[103] Rogach A, Susha A, Caruso F, Sukhorukov G, Kornowski A, Kershaw S, Möhwald H, Eychmüller A, Weller H. Adv Mater 2000; 12: 333.

[104] Lu CH, Qi LM, Cong HL, Wang XY, Yang JH, Yang LL, Zhang DY, Ma JM, Cao WX. Chem Mater 2005; 17: 5218.

[105] Karg M, Pastoriza-Santos I, Pérez-Juste J, Hellweg T, Liz-Marzán LM. Small 2007; 3: 1222.

[106] Ramsden W. Proc R Soc London 1903; 72: 156. 
[107] Pickering SU. J Chem Soc 1907; 91: 2001.

[108] Binks BP. Curr Opin Colloid Interface Sci 2002; 7: 21.

[109] Vignati E, Piazza R, Lockhart TP. Langmuir 2003; 19: 6650.

[110] Horozov TS, Binks BP. Angew Chem Int Ed 2006; 45: 773.

[111] Cauvin S, Colver PJ, Bon SAF. Macromolecules 2005; 38: 7887.

[112] Bon SAF, Colver PJ. Langmuir 2007; 23: 8316.

[113] Voorn DJ, Ming W, van Herk AM. Macromolecules 2006; 39: 2137.

[114] Dupin D, Schmid A, Balmer JA, Armes SP. Langmuir 2007; 23: 11812.

[115] Schmid A, Fujii S, Armes SP. Langmuir 2006; 22: 4923.

[116] Schmid A, Fujii S, Armes SP, Leite CAP, Galembeck F, Minami H, Saito N, Okubo M. Chem Mater 2007; 19: 2435.

[117] Herrera NN, Persoz S, Putaux JL, David L, Bourgeat-Lami E. J Nanosci Nanotechno 2006; 6: 421.

[118] Negrete-Herrera N, Putaux JL, David L, Bourgeat-Lami E. Macromolecules 2006; 39: 9177.

[119] Negrete-Herrera N, Putaux J-L, David L, Haas FD, Bourgeat-Lami E. Macromol Rapid Commun 2007; 28: 1567

[120] Hasell T, Yang JX, Wang WX, Li J, Brown PD, Poliakoff M, Lester E, Howdle SM. J Mater Chem 2007; 17: 4382.

[121] Liu YY, Chen XQ, Wang RH, Xin JH. Mater Lett 2006; 60: 3731.

[122] Chen T, Colver PJ, Bon SAF. Adv Mater 2007; 19: 2286.

[123] Zhang J, Chen KQ, Zhao HY. J Polym Sci Part A Polym Chem 2008; 46: 2632. 
[124] Yang JX, Hasell T, Wang WX, Li J, Brown PD, Poliakoff M, Lester E, Howdle SM. J Mater Chem 2008; 18: 998.

[125] Kumacheva E, Kalinina O, Lilge L. Adv Mater 1999; 11: 231.

[126] Callister WD. Materials Science and Engineering, An Introduction. 7th ed. John Wiley \& Sons, Inc.; 2007. p 585-595.

[127] Coleman JN, Khan U, Blau WJ, Gun'ko YK. Carbon 2006; 44: 1624.

[128] Bonderer LJ, Studart AR, Gauckler LJ. Science 2008 ; 319 : 1069.

[129] Lin Y, Zhou B, Fernando KAS, Liu P, Allard LF, Sun Y-P. Macromolecules 2003; 36: 7199.

[130] Zhou TH, Ruan WH, Rong MZ, Zhang MQ, Mai YL. Adv Mater 2007; 19: 2667.

[131] Shi JH, Yang BX, Pramoda KP, Goh SH. Nanotechnology 2007; 18: 375704.

[132] Xie L, Qiu F, Lu HB, Yang YL. Macromolecules 2007; 40: 3296.

[133] Creton C, Kramer EJ, Hui CY, Brown HR. Macromolecules 1992; 25: 3075.

[134] Norton LJ, Smigolova V, Pralle MU, Hubenko A, Dai KH, Kramer EJ. Macromolecules 1995; 28: 1999.

[135] Dai CA, Kramer EJ, Washiyama J, Hui CY. Macromolecules 1996; 29: 7536.

[136] Creton C, Brown HR, Shull KR. Macromolecules 1994; 27: 3174.

[137] Bureau L, Léger L. Langmuir 2004; 20: 4253.

[138] Casoli A, Brendlé M, Schultz J, Auroy P, Reiter G. Langmuir 2001; 17: 388.

[139] Wang T, Dalton AB, Keddie JL, submitted. 
[140] Mezzenga R, Ruokolainen J, Fredrickson GH, Kramer EJ, Moses D, Heeger AJ, Ikkala O. Science 2003 ; 299: 1872

[141] Kotov NA, Liu YF, Wang SP, Cumming C, Eghtedari M, Vargas G. Motamedi M, Nichlos J, Cortiella J. Langmuir 2004; 20: 7887.

[142] Zhang YJ, Wang SP, Eghtedari M, Motamedi M, Kotov NA. Adv Funct Mater $2005 ; 15: 725$.

[143] Lee J, Shanbhag S, Kotov NA. J Mater Chem. 2006; 16: 3558.

[144] Rogers JA. Science 2001; 291: 1502.

[145] Cheng W, Wang J, Jonas U, Fytas G, Stefanou N. Nat Mater 2006; 5: 830.

[146] Stein A, Li F, Denny NR. Chem Mater 2008; 20: 649.

[147] Lee K, Asher SA. J Am Chem Soc 2000; 122: 9534.

[148] Cumpston BH, Ananthavel SP, Barlow S, Dyer DL, Ehrlich JE, Erskine LL, Heikal AA, Kuebler SM, Lee I-YS, McCord-Maughon D, Qin JQ, Röckel H, Rumi M, Wu X-L, Marder SR, Perry JW. Nature 1999; 398: 51.

[149] Arsenault AC, Puzzo DP, Manners I, Ozin GA. Nature Photonics 2007; 1: 468.

[150] Xue Z, Wiese H, U.S. patent US7094830B2 2006.

[151] Tiarks F, Leuninger J, Wagner O, Jahns E, Wiese H. Surf Coat Intern 2007; 90: 221. 


\section{Figure captions}

Figure 1. (a) Overview of the horizontal deposition process of polymer colloids (i.e. film formation). (b) AFM phase image of an ordered close-packed array of polymer colloids obtained by the horizontal deposition process. Average particle size is $~ 200$ $\mathrm{nm}$; image size is $2 \mu \mathrm{m} \times 2 \mu \mathrm{m}$.

Figure 2. (a) Scheme of the process of vertical deposition of polymer colloids. Redrawn after ref. [32]. (b) SEM of one layer and (c) seven-layer silica micropheres on a glass substrate processed by vertical deposition. The silica diameter is $\sim 230 \mathrm{~nm}$. Reprinted with permission from ref. [33]. Copyright (c) 2006 American Chemical Society.

Figure 3. (a) Scheme of the spin-coating process of polymer colloids. (b) AFM phase image of an array of separated polymer colloid particles obtained by spin-coating. Image size is $2 \mu \mathrm{m} \times 2 \mu \mathrm{m}$.

Figure 4. (a) Colloidal particle assembly on a chemically-patterned surface using the vertical deposition process. Redrawn after ref. [47]. (b) Colloidal particle assembly on surface channels using the horizontal deposition process. (c) Optical micrograph of polystyrene latex particles on a patterned polyelectrolyte surface. Reprinted with permission from ref. [45]. Copyright (C) 2000 American Chemical Society. (d) SEM image of poly(styrene) latex particles assembled within a channel with a $10 \mu \mathrm{m}$ width and a $1.5 \mu \mathrm{m}$ depth. Poly(styrene) particle size is $1.75 \mu \mathrm{m}$. Reprinted with permission from ref. [46]. Copyright Wiley-VCH Verlag GmbH \& Co. KGaA. 
Figure 5. (a) SEM image of a poly(styrene) latex particle array obtained by a floating self-assembly process. Particle size is $10 \mu \mathrm{m}$. The inset shows the corresponding "inverse opal structure" obtained by filling in the interstitial void space and removing the polymer particles. Reprinted with permission from ref. [51]. Copyright @ 2005 American Chemical Society. (b) SEM image of a close-packed array of polymer colloids obtained by centrifugation. Particle size is $1 \mu \mathrm{m}$. Ref [52]-Reproduced by permission of The Royal Society of Chemistry.

Figure 6. (a) Direct L-J interaction force $F_{D}(r)$ between two nanoparticles of varying diameter, $\sigma_{\mathrm{c}}$, (as indicated in the legend) as a function of their separation distance, $r$. Simulated using Equation 2. (b) Interaction potential of two parallel SWNTs (in vacuum) as a function of the tube-tube distance, $r$, measured from the centres of the tubes ( $D$ is assumed here to be $1.1 \mathrm{~nm}$ ). Reprinted with permission from ref. [59]. Copyright @ 2004 American Chemical Society.

Figure 7. (a) A TEM image of gold nanoparticles coated with poly(4-vinylpyridine) by surface-initiated atom-transfer radical polymerization at ambient conditions. Reprinted with permission from ref. [70]. Copyright (C) 2007 American Chemical Society. (b) AFM phase image of isolated multi-wall carbon nanotubes stabilized by physisorbed poly(vinyl pyrrolidone) after being deposited on mica. Image size is 2 $\mu \mathrm{m} \times 2 \mu \mathrm{m}$.

Figure 8. (a) Results of Monte Carlo simulations of the polymer-mediated force $F_{\mathrm{P}}(r)$ at different grafting densities ranging from $\rho_{\mathrm{a}}{ }^{*}=0.5$ to 5.0 as indicated in the legend. $\sigma_{\mathrm{c}}$ is assumed here to be 10 times the polymer segment length, and the chain length is 
taken as $N=30$. The direct L-J interaction force $F_{\mathrm{D}}(r)$ is also shown for comparison. Reprinted with permission from ref. [75]. Copyright (c) 2006 American Chemical Society. (b) The total interaction energy between two parallel CNTs with end-tethered polymers (chain length $N=50$ (line) and $N=100$ (dotted line). Ref. [60]-Reproduced by permission of The Royal Society of Chemistry.

Figure 9. (a) Schematic illustration of the horizontal deposition process for polymer colloid/nanotube blends. (b) SEM image of a nanocomposite comprised of a segregated network of carbon nanotubes in silica particles. Reprinted with permission from ref. [80]. Copyright Wiley-VCH Verlag GmbH \& Co. KGaA. (c) SEM image of an ordered colloidal nanocomposite obtained by accelerated vertical deposition. Larger PS latex spheres with $\sigma_{\mathrm{c}}=1.28 \mu \mathrm{m}$ are fully surrounded by smaller silica spheres with $\sigma_{\mathrm{c}}=290 \mathrm{~nm}$. Reprinted with permission from ref. [13]. Copyright Wiley-VCH Verlag GmbH \& Co. KGaA.

Figure 10. Schematic illustration of the assembly of various inorganics (particles, platelets (clay), or nanotubes) on polymer colloid cores. Either the polymer colloids, the inorganics, or both are pre-treated to enable hetero-flocculation or precipitation to be triggered in the colloidal suspensions.

Figure 11. (a) SEM images of $9.6 \mu \mathrm{m}$ sulfonated PS latex particles encapsulated with $\mathrm{NH}_{2}$-functionalized MWNTs, and (b) the surface of one of these particles. Reprinted with permission from ref. [91]. Copyright IOP Publishing Ltd. 
Figure 12. (a) Synthesis scheme for nano-inorganic-armored colloidal hybrid particles via Pickering polymerization. Redrawn after ref. [111]. (b) SEM image of laponite clay-armored polystyrene latex. Scale bar indicates $200 \mathrm{~nm}$. Reprinted with permission from ref. [111]. Copyright (c) 2005 American Chemical Society. (c) Montmorillonite clay-armored polyacrylamide latex particles. Scale bar indicates 1 $\mu \mathrm{m}$. Reprinted with permission from ref. [113]. Copyright () 2006 American Chemical Society.

Figure13. (a) TEM micrograph of cryo-tomed cross-section of poly(sty-co$\mathrm{BuA}$ )/laponite composite latex film obtained by horizontal deposition. A "honeycomb" arrangement of the laponite is observed. Reprinted with permission from ref. [119]. Copyright Wiley-VCH Verlag GmbH \& Co. KGaA. (b) Electron micrograph of an ordered network of single-wall carbon nanotubes obtained by etching the PS from a PS-SWNT blend nanocomposite fabricated by the vertical deposition method. Ref. [101]-Reproduced by permission of The Royal Society of Chemistry.

Figure 14. (a) The dependence of the adhesion energy of an acrylic/nanotube blend nanocomposite adhesives on $\tan \delta / \mathrm{E}^{\prime}$ of the bulk material. The $\tan \delta / \mathrm{E}^{\prime}$ values can be tuned through the interface dispersant molecular weight. Plotted from data in Table 1 of ref. [85]. (b) An illustration of hydrophilic polymers physisorbed on the carbon nanotube surface: low molecular weight polymer with high grafting density $(\Sigma)$ (left) and high molecular weight polymer with a lower $\Sigma$ (right). 
Table 1. Examples of Blends of Polymer Colloids with Inorganic Nanoparticles

\begin{tabular}{|c|c|c|c|c|}
\hline Polymer & $\begin{array}{c}\text { Inorganic } \\
\text { nanoparticle }\end{array}$ & $\begin{array}{c}\text { Dispersant for } \\
\text { the inorganic } \\
\text { particles }\end{array}$ & $\begin{array}{c}\text { Film formation } \\
\text { method }\end{array}$ & References \\
\hline PVAc & SWNT & GA & $\begin{array}{c}\text { Horizontal } \\
\text { deposition }\end{array}$ & {$[76,77]$} \\
\hline P(St-BuA $)$ & MWNT & SDS & $\begin{array}{c}\text { Horizontal } \\
\text { deposition }\end{array}$ & {$[81]$} \\
\hline PS, PMMA & SWNT & SDS, GA & $\begin{array}{c}\text { Horizontal } \\
\text { deposition }\end{array}$ & {$[82,83]$} \\
\hline P(BuA-co-AA) & SWNT & PVA & $\begin{array}{c}\text { Horizontal } \\
\text { deposition }\end{array}$ & {$[84]$} \\
\hline P(BuA-co-AA) & MWNT & $\begin{array}{c}\text { PVP, PVA, } \\
\text { SDS, TX }\end{array}$ & $\begin{array}{c}\text { Horizontal } \\
\text { deposition }\end{array}$ & {$[85]$} \\
\hline PVAc & Carbon black & - & $\begin{array}{c}\text { Horizontal } \\
\text { deposition }\end{array}$ & {$[86]$} \\
\hline Sulfonated latex & $\mathrm{Au}$ & - & $\begin{array}{c}\text { Vertical } \\
\text { deposition }\end{array}$ & {$[87,88]$} \\
\hline PS & $\mathrm{SiO}_{2}$ & - & $\begin{array}{c}\text { Vertical } \\
\text { deposition }\end{array}$ & {$[12,13]$} \\
\hline
\end{tabular}

$\mathrm{PVP}=$ poly $($ vinyl pyrrolidone $) ; \mathrm{PVA}=$ poly $($ vinyl alcohol $) ; \mathrm{SDS}=$ sodium dodecyl sulfate; $\mathrm{GA}=$ gum arabic; $\mathrm{TX}=$ Triton $\mathrm{X}-100$ (surfactant) 
Table 2. Examples of Hybrid Particles Obtained via Heteroflocculation or Precipitation

\begin{tabular}{|c|c|c|c|c|}
\hline Polymer & Inorganic phase & $\begin{array}{l}\text { Polymer colloid } \\
\text { size }(\mu \mathrm{m})\end{array}$ & Method & Reference \\
\hline PS & $\begin{array}{c}\mathrm{TiO}_{2}, \mathrm{SiO}_{2} \\
\text { Clay(Laponite) }\end{array}$ & $0.21 \sim 0.64$ & opposite charge & [96] \\
\hline PS & $\mathrm{Fe}_{3} \mathrm{O}_{4}$ & 0.64 & opposite charge & [93] \\
\hline PS & $\mathrm{Ag}$ & $0.23 \sim 0.605$ & specific reaction & {$[94,97]$} \\
\hline PS & $\mathrm{Au}$ & $0.4,1$ & specific reaction & {$[97,98]$} \\
\hline PS & $\mathrm{ZnS}$ & 0.275 & specific reaction & [99] \\
\hline PS & $\mathrm{CdS}$ & 0.13 & opposite charge & [100] \\
\hline PS & CdTe & 0.468 & $\begin{array}{c}\text { solvent } \\
\text { treatment, } \\
\text { opposite charge }\end{array}$ & [90] \\
\hline PS & SWNT & 0.4 & $\begin{array}{l}\text { I stacking } \\
\text { interaction }\end{array}$ & [101] \\
\hline Sulfonated PS & MWNT & $5 \sim 10$ & pH adjustment & [91] \\
\hline Sulfonated PS & $\mathrm{CdTe}(\mathrm{S})$ & 0.64 & opposite charge & {$[102,103]$} \\
\hline P(St-MAA-AA) & $\mathrm{CaCO}_{3}$ & 0.38 & specific reaction & [104] \\
\hline P(St-MAA-AA) & $\mathrm{Cu}_{2} \mathrm{O}$ & 0.08 & specific reaction & [104] \\
\hline PNIPAM & $\mathrm{Au}$ & $\sim 0.45$ & opposite charge & [105] \\
\hline PMMA & $\begin{array}{c}\text { Clay } \\
\text { (Montmorillonite } \\
\text { and Laponite) }\end{array}$ & 0.2 & ion exchange & [92] \\
\hline
\end{tabular}


Table 3. Examples of "Armored” Hybrid Particles

\begin{tabular}{|c|c|c|c|c|}
\hline Polymer & Inorganic phase & Colloid size $(\mu \mathrm{m})$ & $\begin{array}{c}\text { Synthesis } \\
\text { Method }\end{array}$ & References \\
\hline PS & $\begin{array}{c}\text { Clay } \\
\text { (Laponite) }\end{array}$ & $\sim 0.3$ & $\begin{array}{c}\text { Pickering } \\
\text { polymerization }\end{array}$ & {$[111,112]$} \\
\hline PAAm & $\begin{array}{c}\text { Clay } \\
(\text { Montmorillonite })\end{array}$ & $0.7 \sim 1$ & $\begin{array}{c}\text { Pickering } \\
\text { polymerization }\end{array}$ & {$[113]$} \\
\hline PS & $\mathrm{TiO}_{2}$ & $1,20 \sim 50$ & $\begin{array}{c}\text { Pickering } \\
\text { polymerization }\end{array}$ & {$[121,122]$} \\
\hline PMMA & $\begin{array}{c}\text { Clay } \\
\text { (Montmorillonite })\end{array}$ & $\sim 0.1$ & $\begin{array}{c}\text { Pickering } \\
\text { polymerization }\end{array}$ & {$[123]$} \\
\hline P(St-BuA) & $\begin{array}{c}\text { Clay } \\
(\text { Laponite })^{\text {In-situ }}\end{array}$ & {$[119]$} \\
\hline PMMA & $\mathrm{Fe}_{3} \mathrm{O}_{4}$ & 400 & $\begin{array}{c}\text { In-situ } \\
\text { polymerisation }\end{array}$ & {$[120]$} \\
\hline PS & $\mathrm{Fe}_{3} \mathrm{O}_{4}$ & $1 \sim 3$ & $\begin{array}{c}\text { In-situ } \\
\text { polymerisation }\end{array}$ & {$[124]$} \\
\hline P2VP & $\mathrm{Silica}_{\mathrm{V}}$ & $0.18 \sim 0.22$ & $\begin{array}{c}\text { Emulsion } \\
\text { polymerization }\end{array}$ & {$[114]$} \\
\hline PS & Silica & $0.2 \sim 3.3$ & $\begin{array}{c}\text { Dispersion } \\
\text { polymerization }\end{array}$ & {$[115,116]$} \\
\hline
\end{tabular}




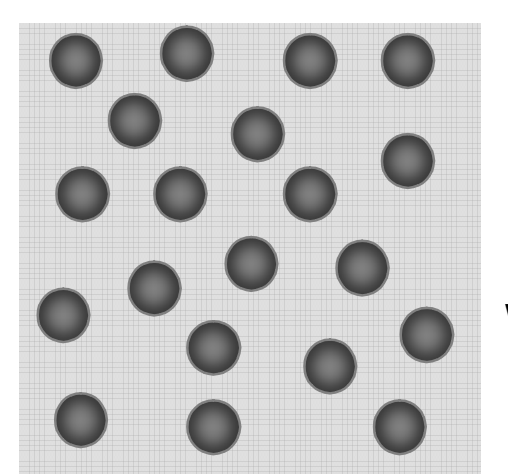

Polymer colloids or hybrids a

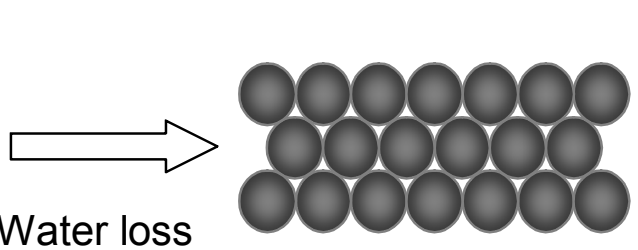

Water loss

Deformation
of particles

T $>$ MFFT



Dodecahedral structure

Close-packing 
Lifting direction

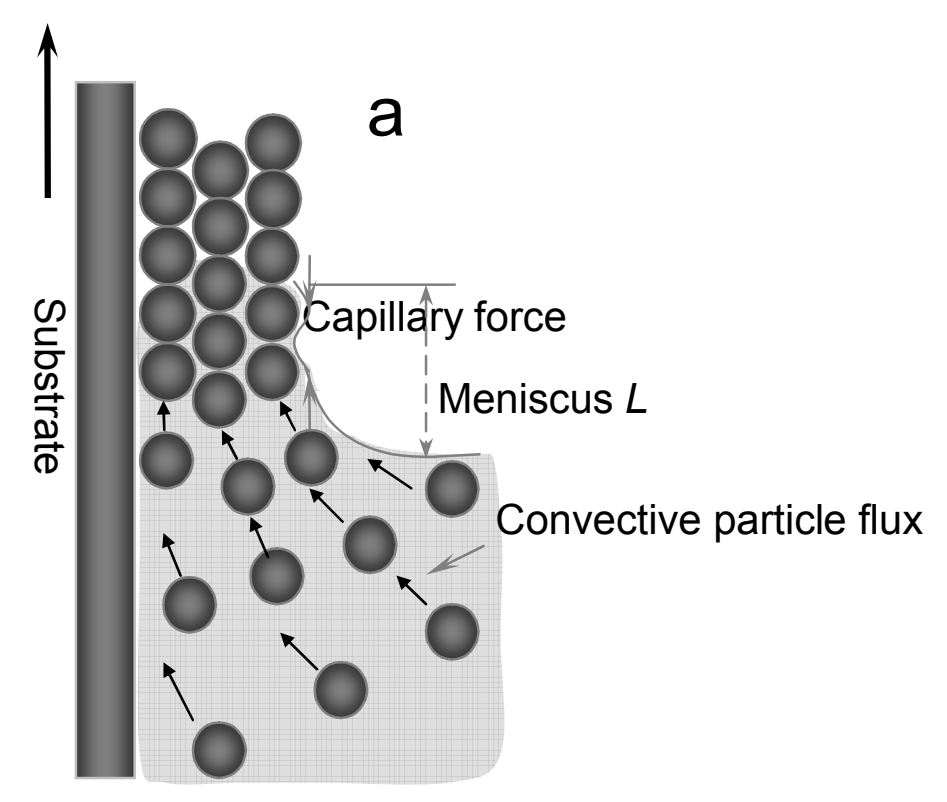


Click here to download high resolution image

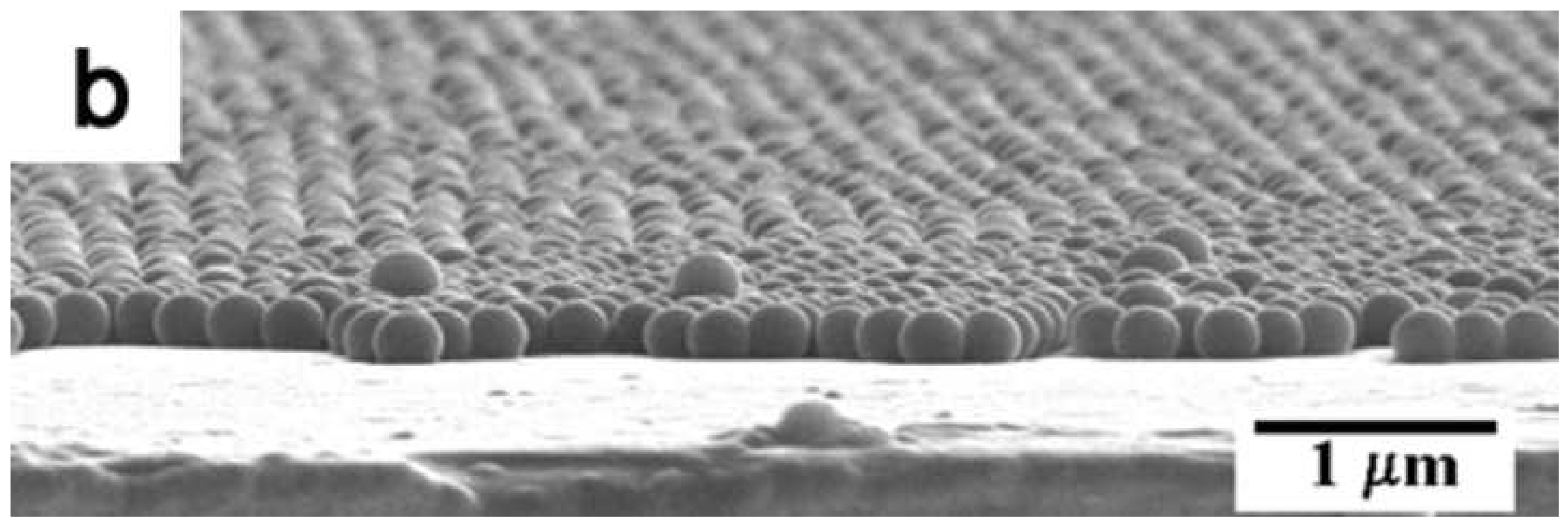








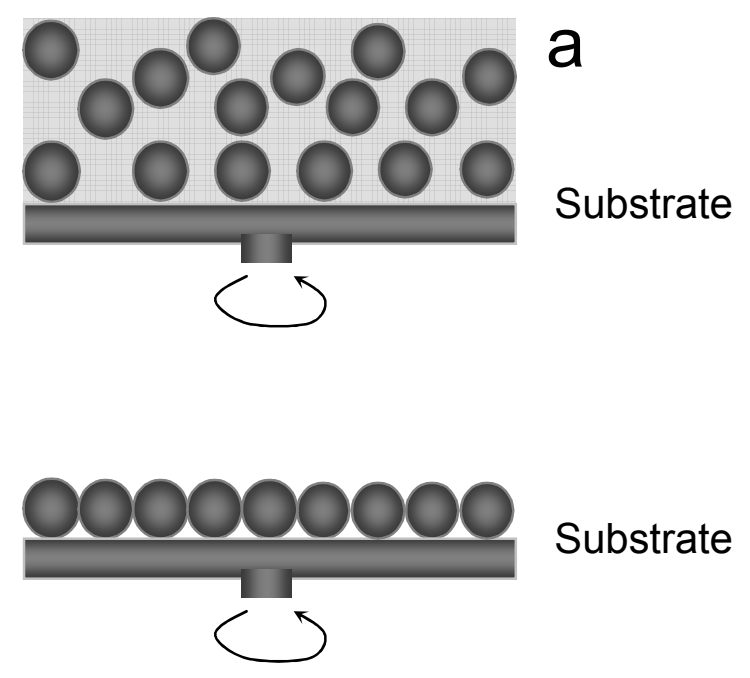
Click here to download high resolution image

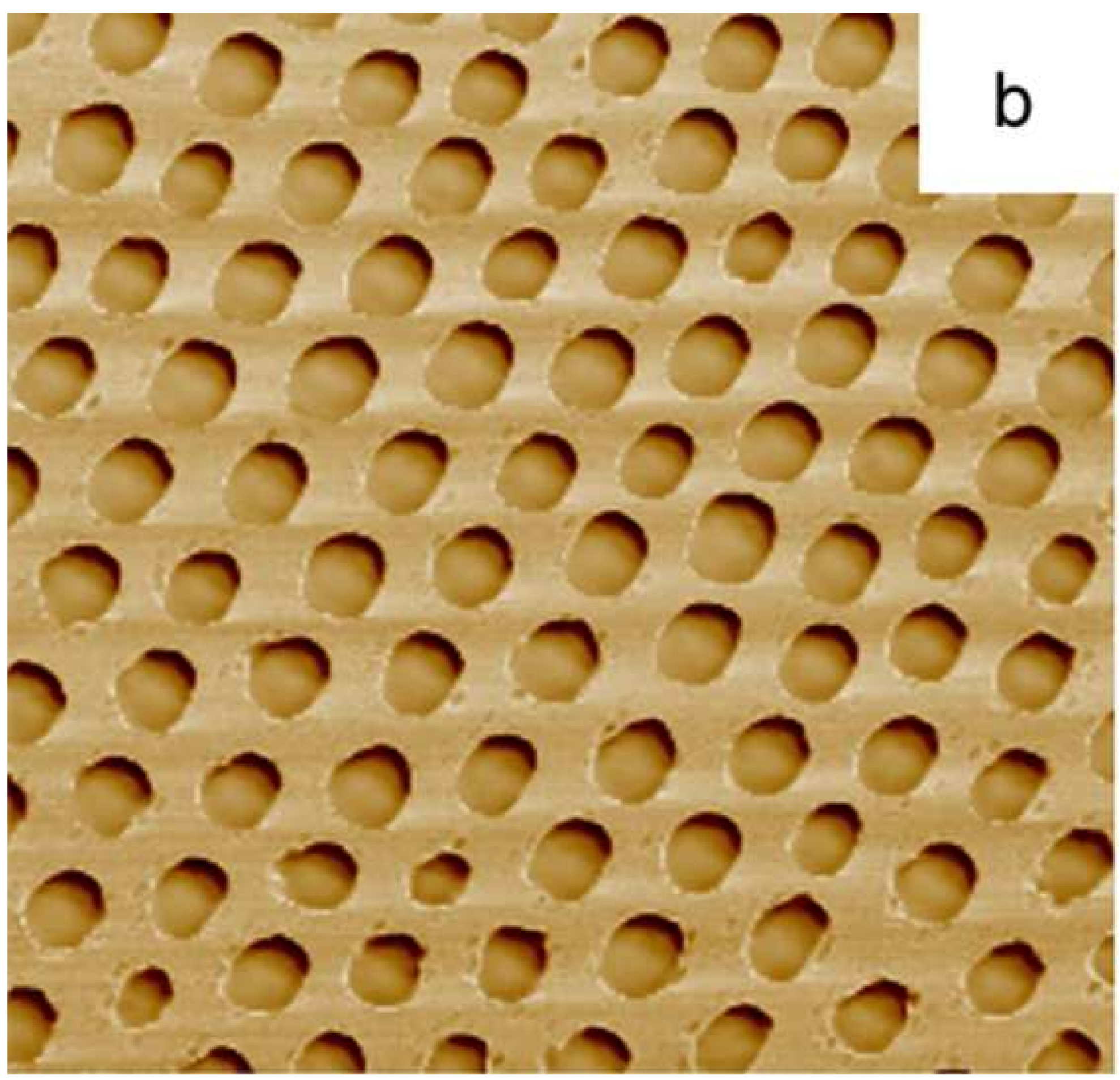



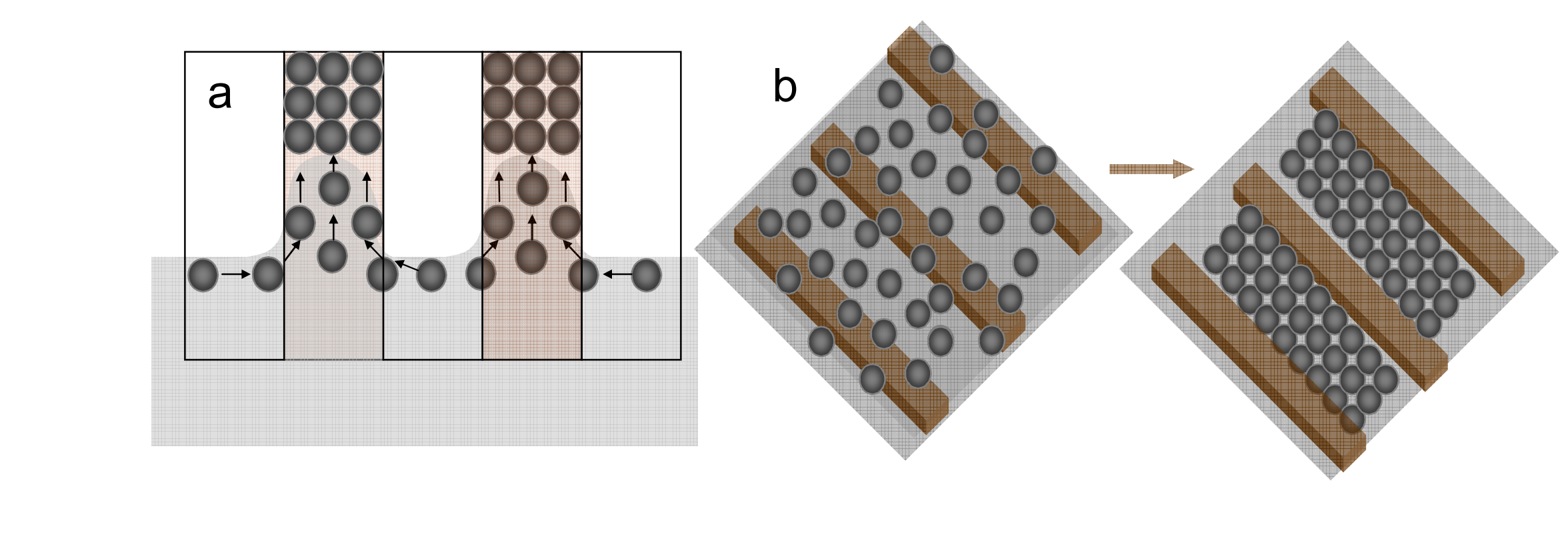

\section{Figure $4 a \& 4 b$}

(2)

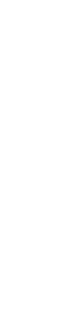

a


Click here to download high resolution image




Figure $4 d$
Click here to download high resolution image


.

(
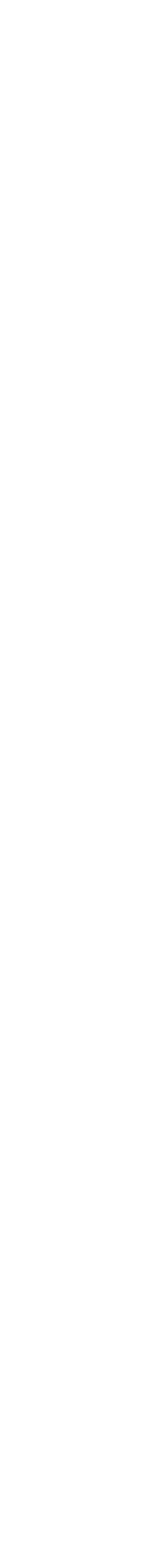


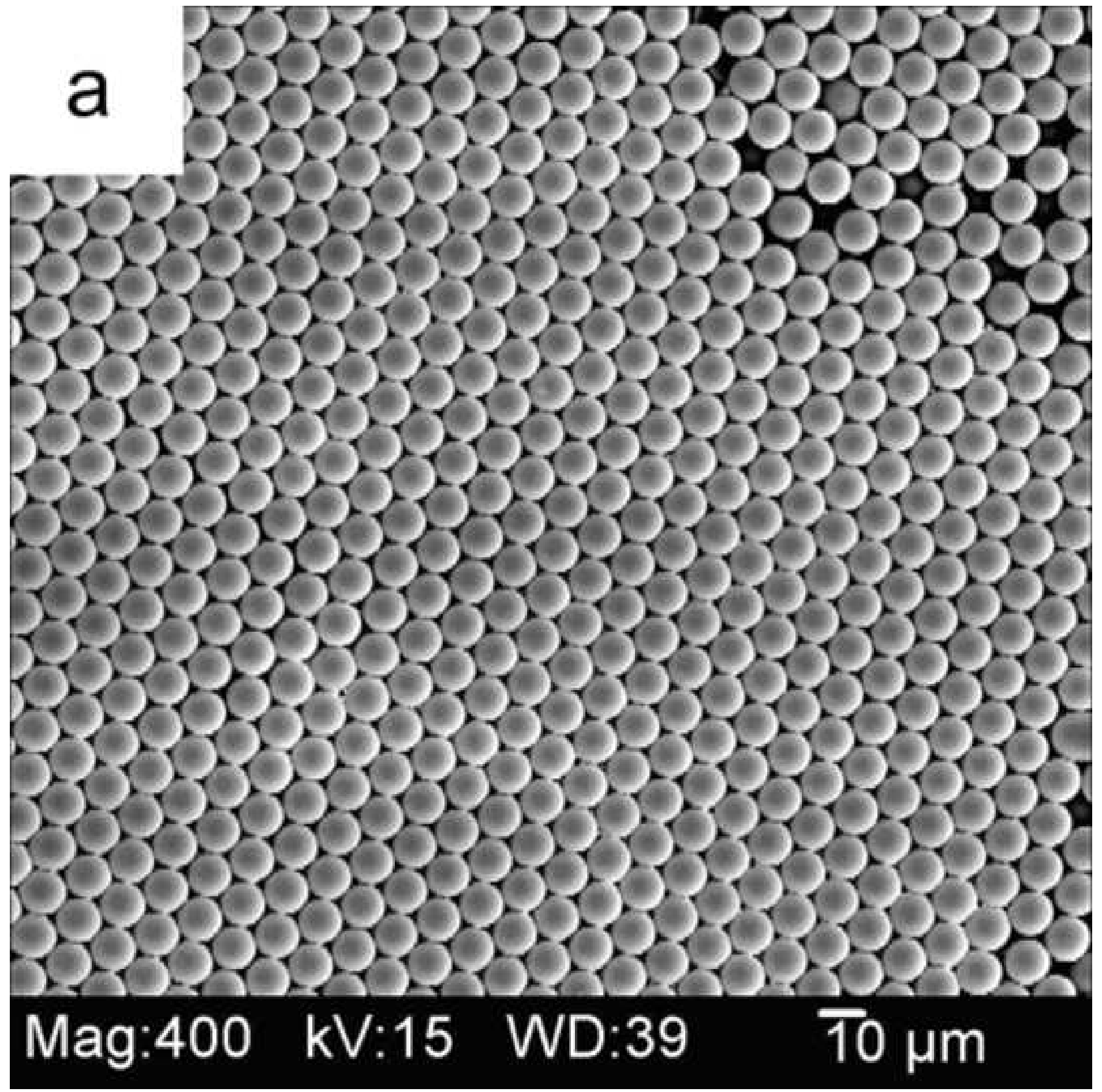




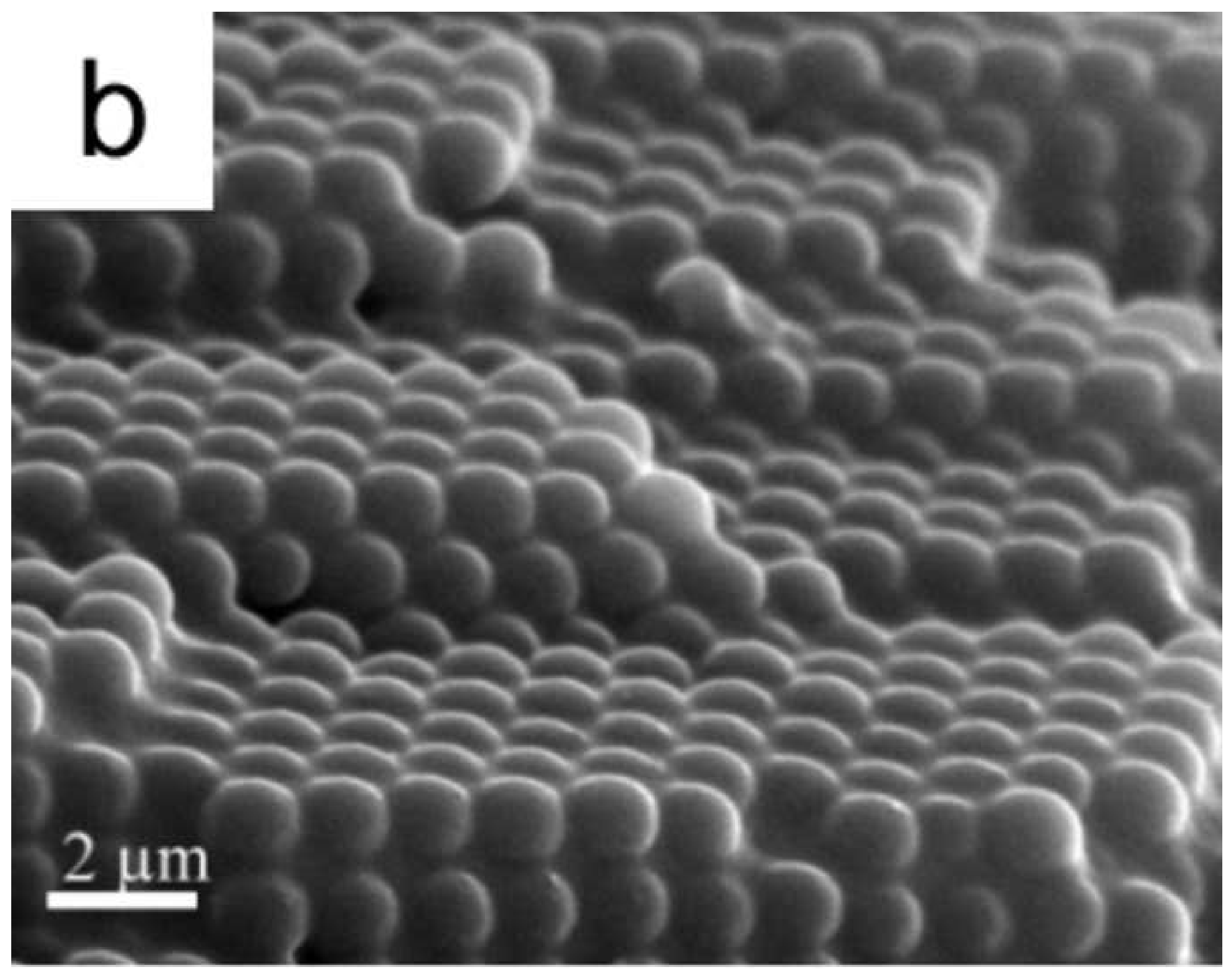



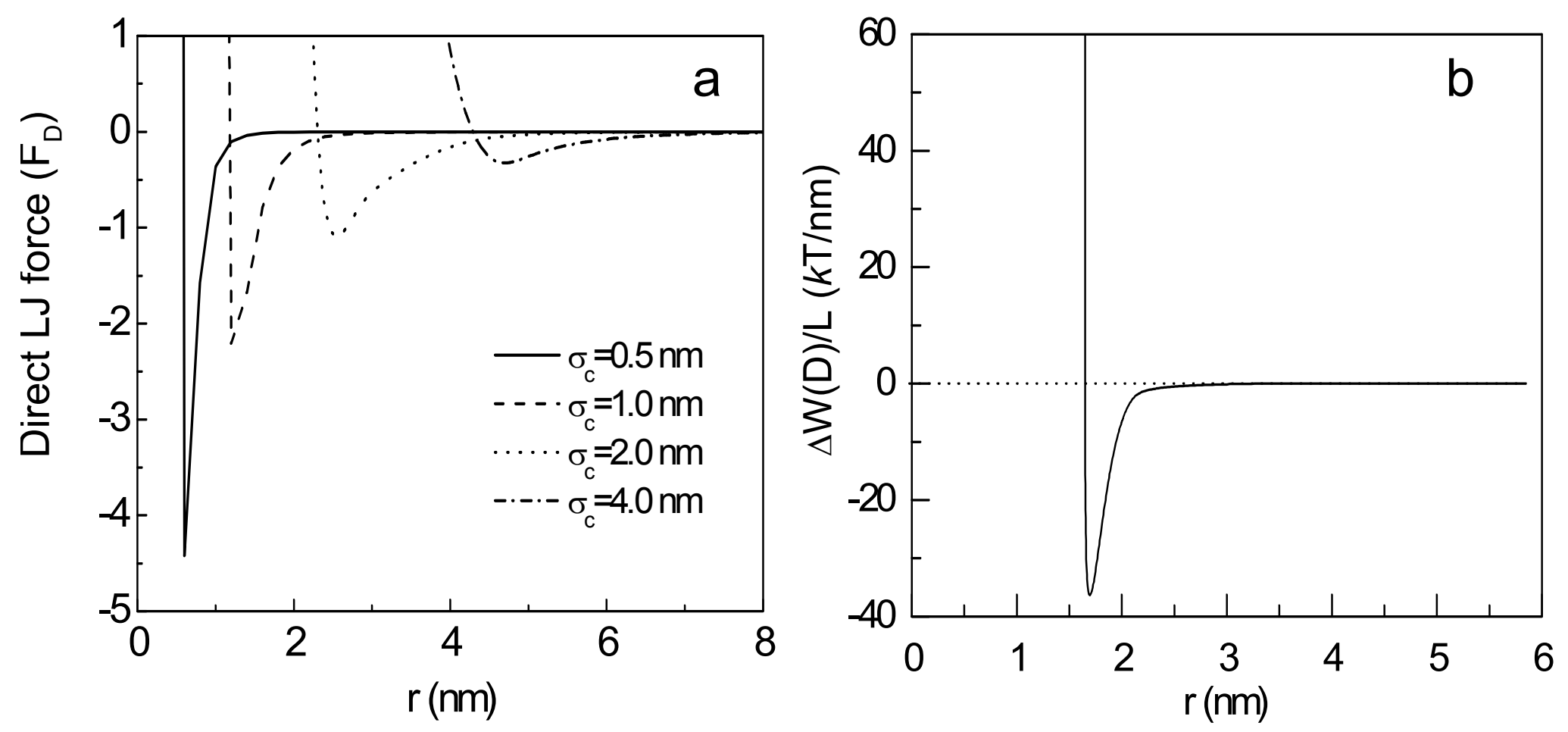
Click here to download high resolution image

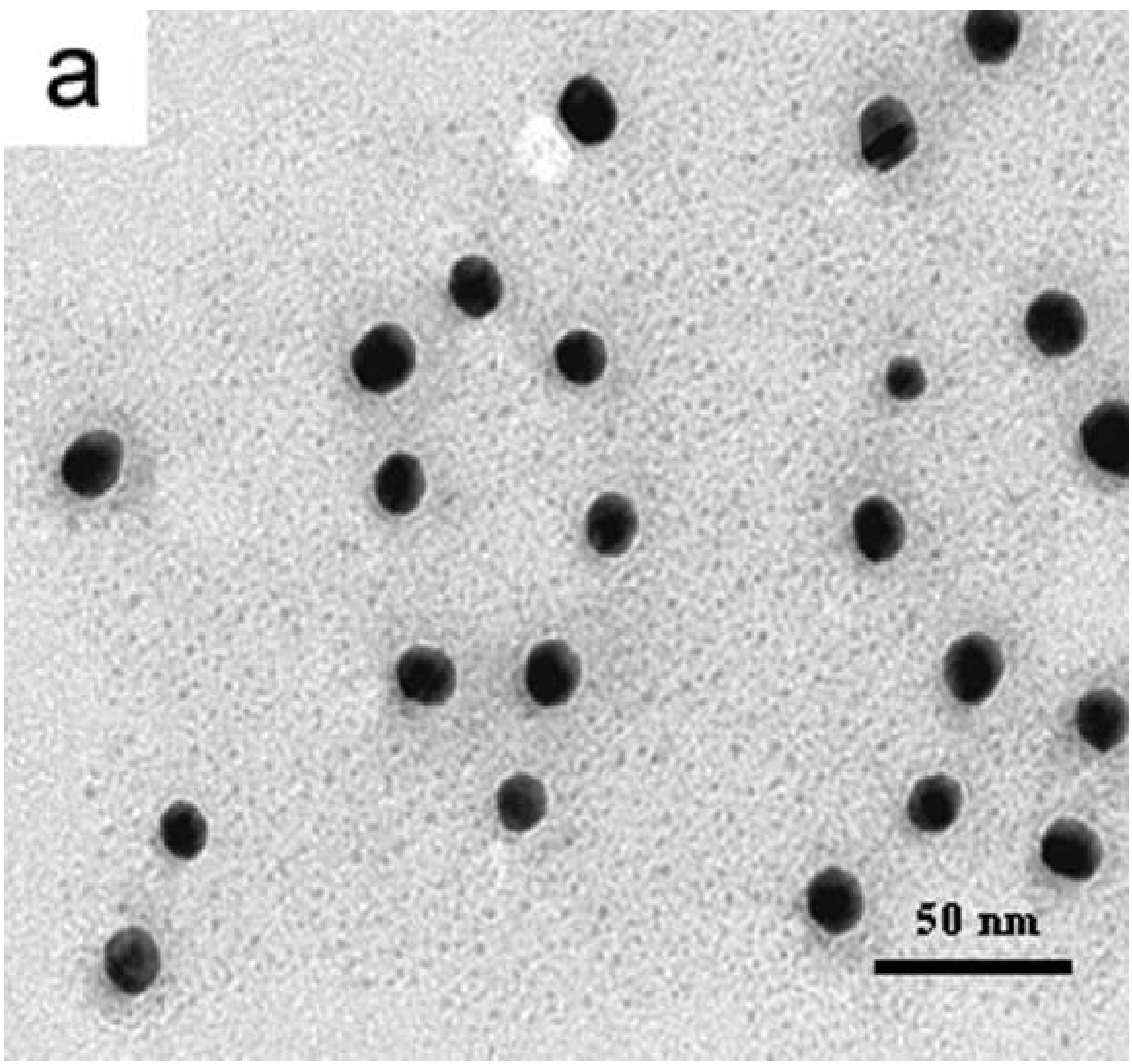


Click here to download high resolution image





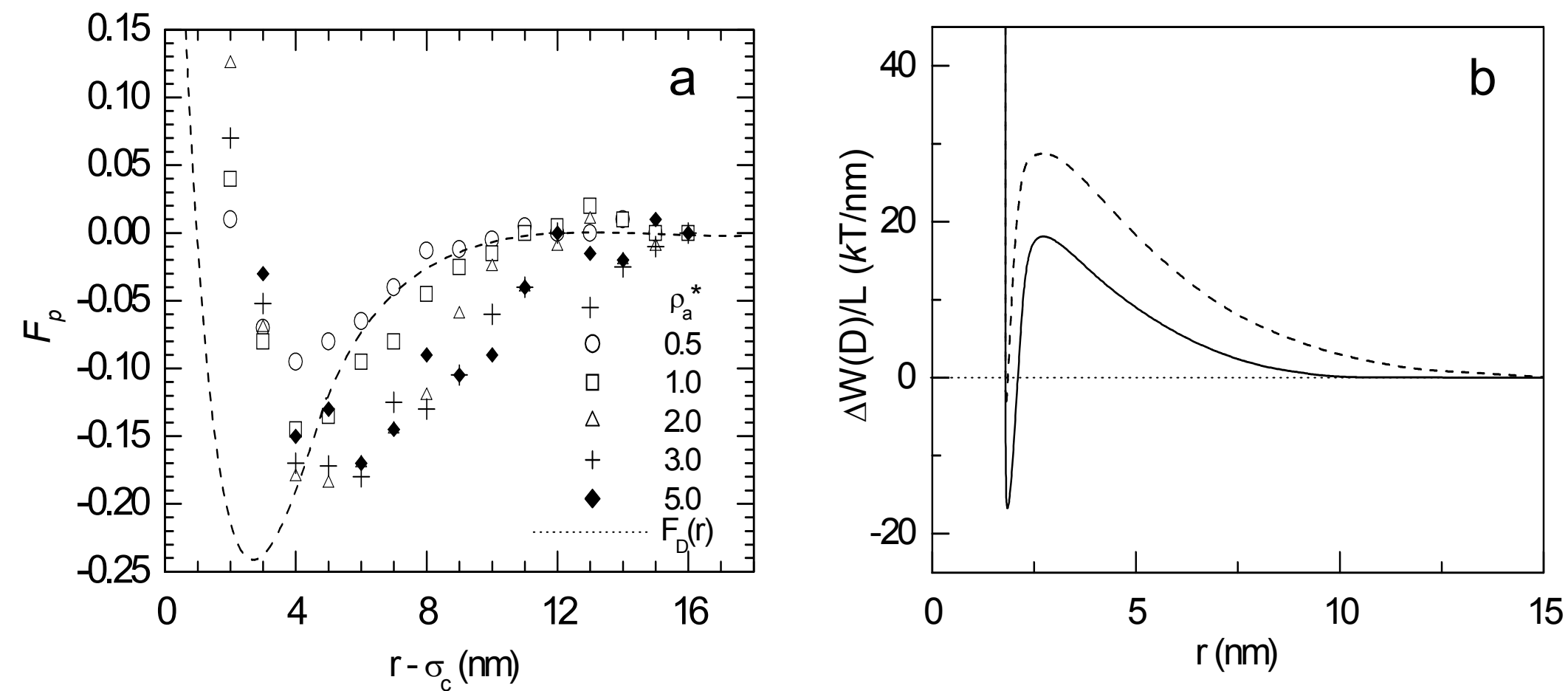




Polymer colloid hybrids a

T> MFFT

Water loss

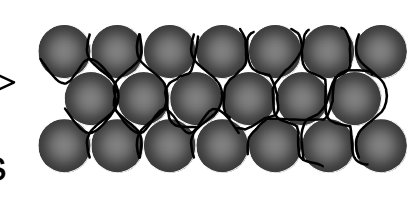

\section{Deformation}

of particles

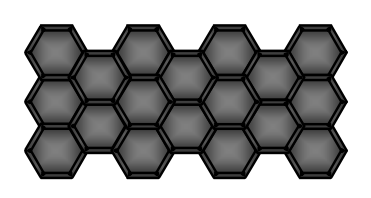

Segregated network

Close-packing 
Click here to download high resolution image

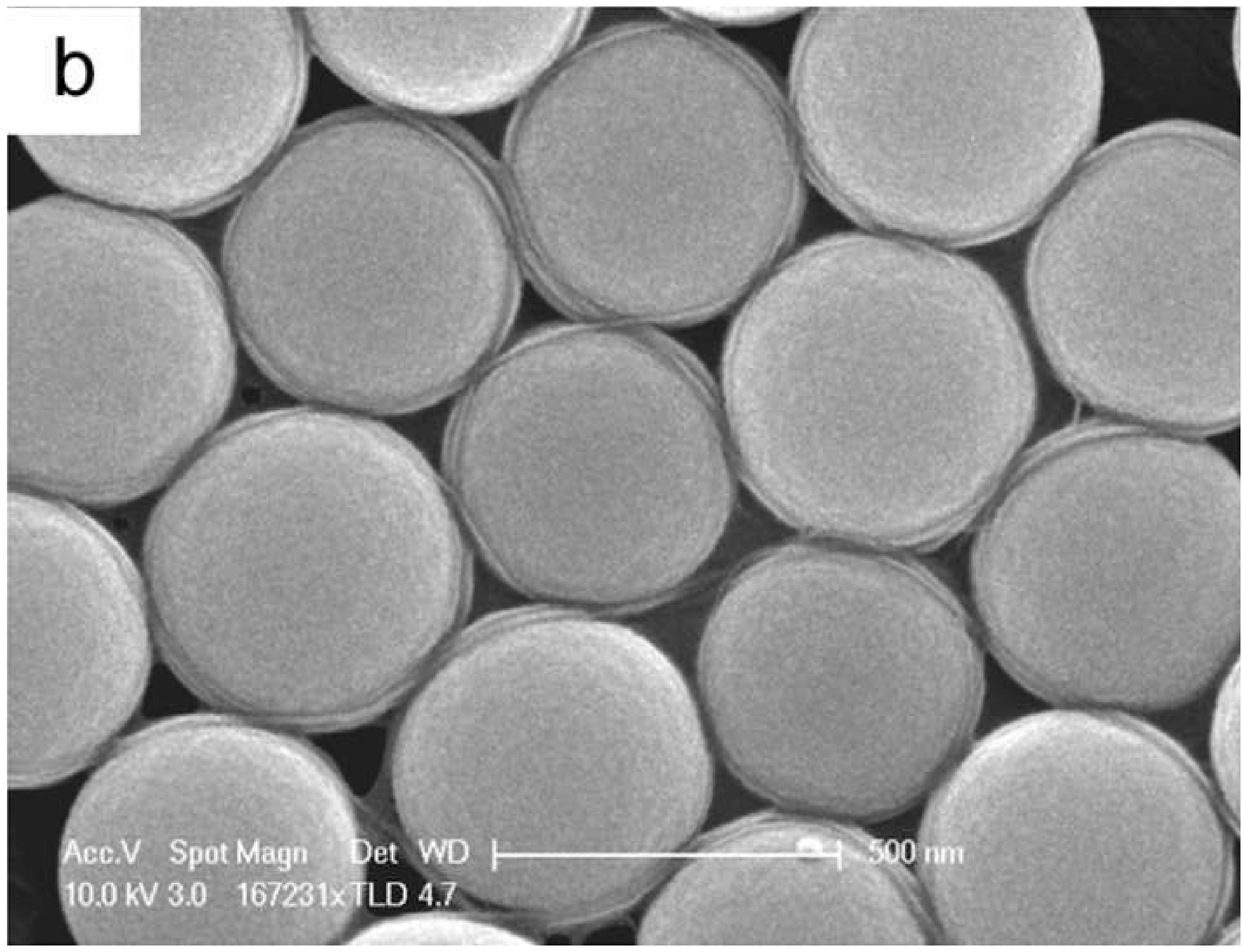


Click here to download high resolution image


(1) , (9) $12=$

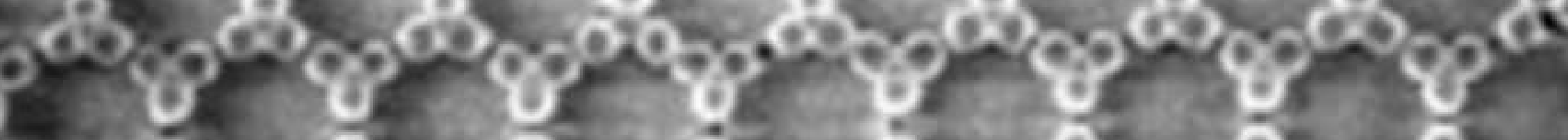
(1) 4.

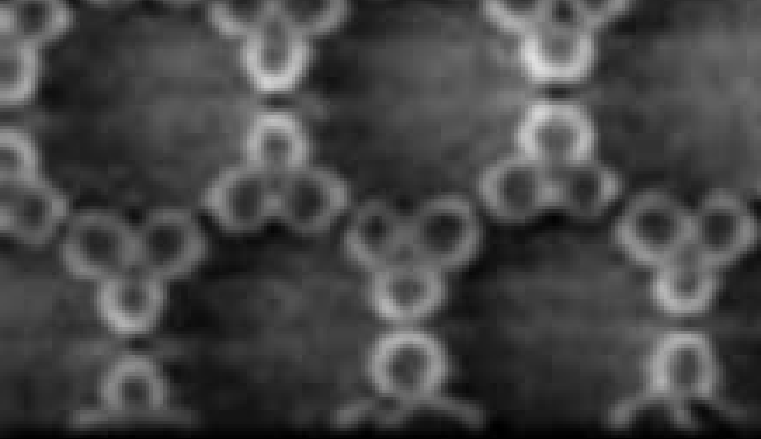
1. $8 \mathrm{kV} \times 9.86 \mathrm{k}$ ' $3.33 \mathrm{~m}$

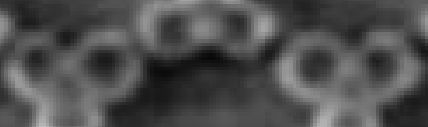

sis 


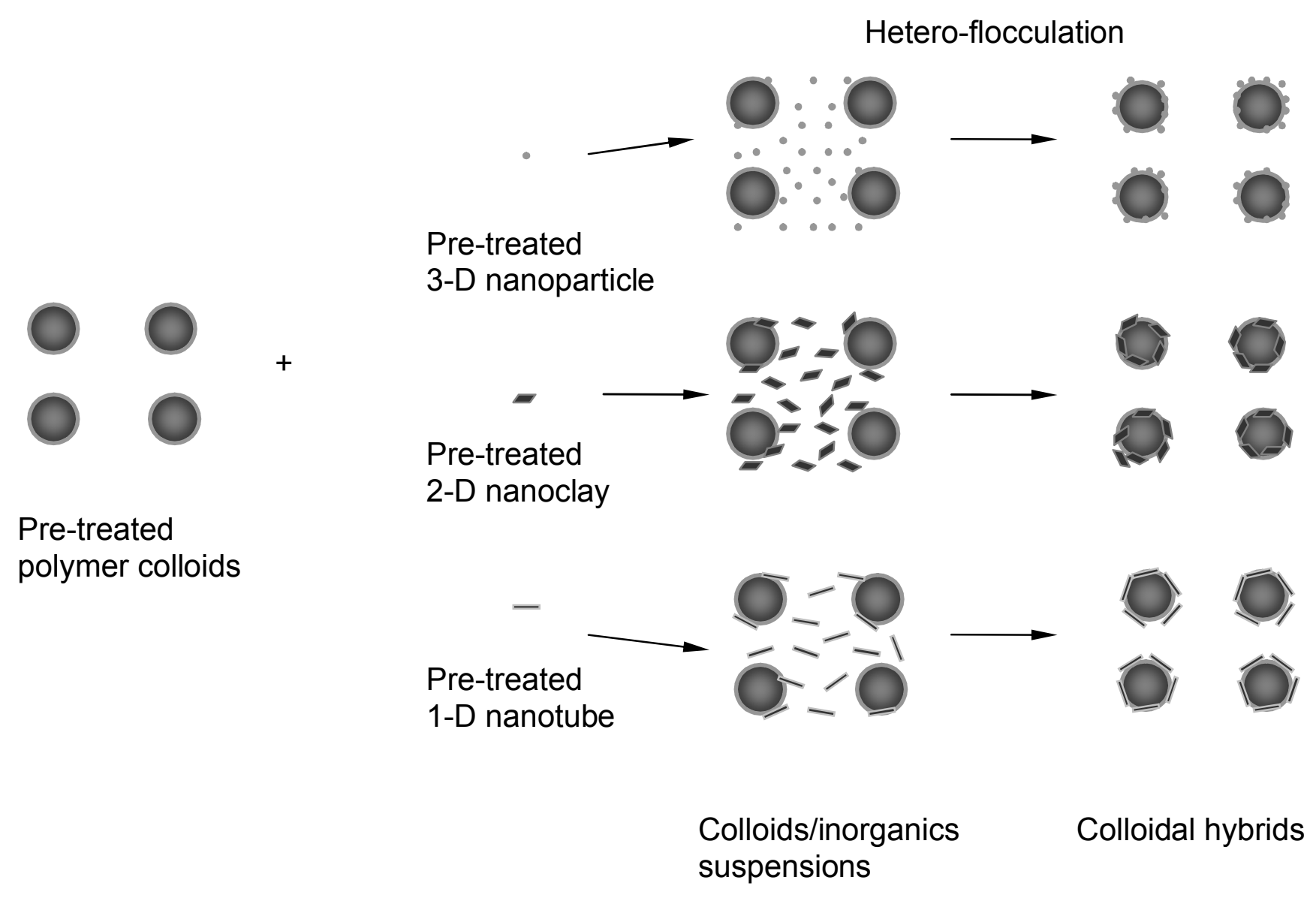


Click here to download high resolution image

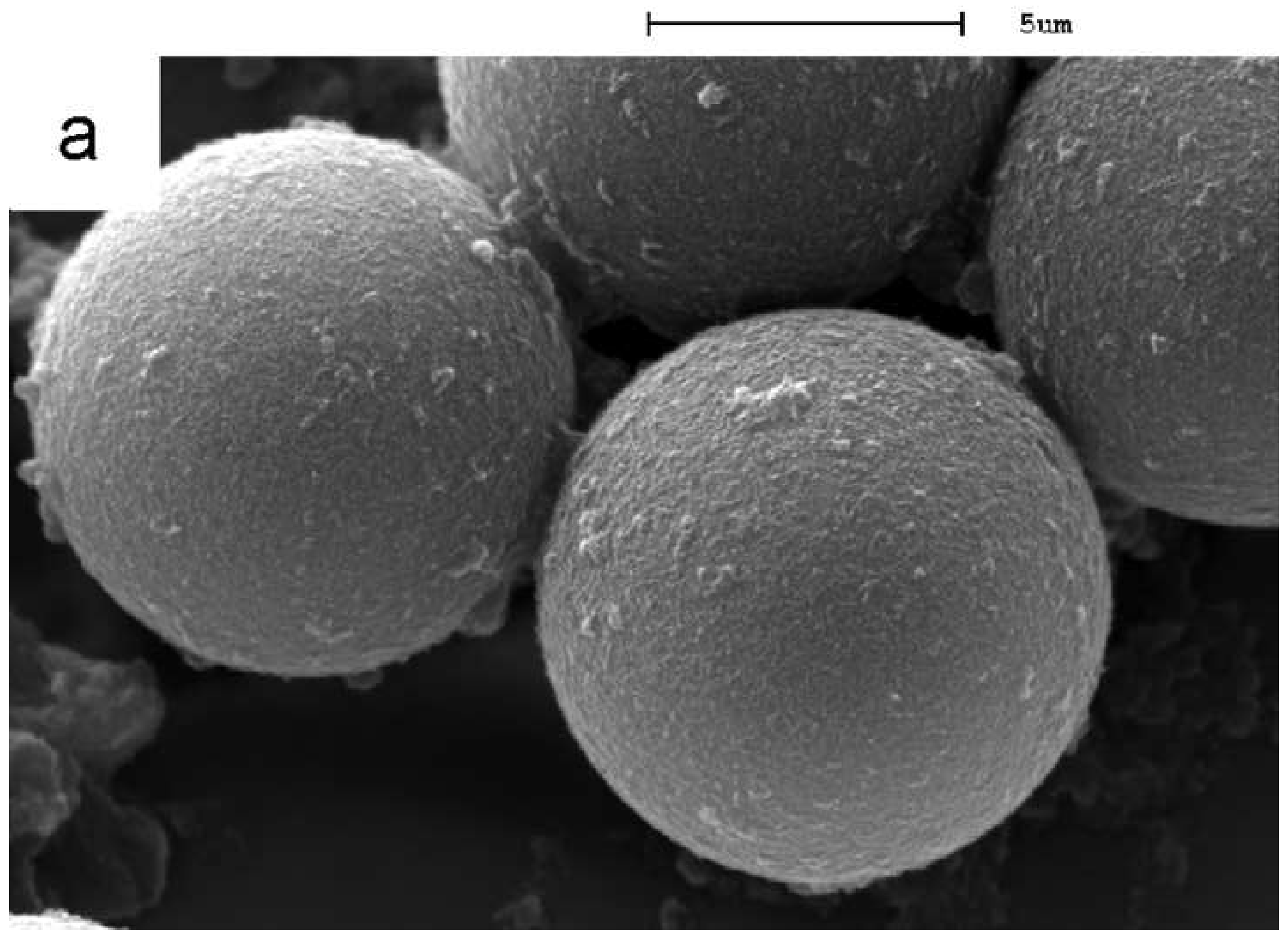

crownoad high resolution imag 
Click here to download high resolution image

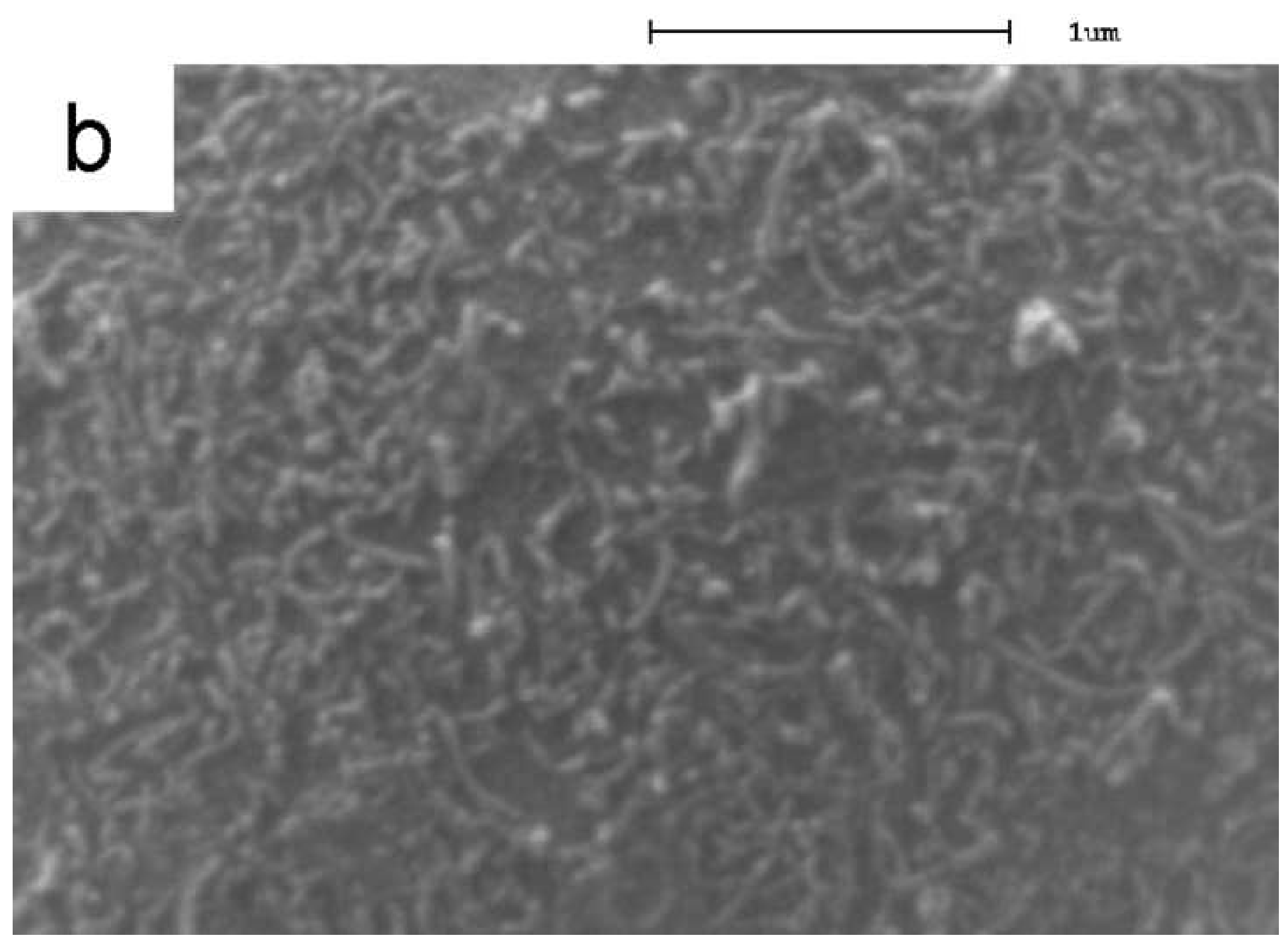




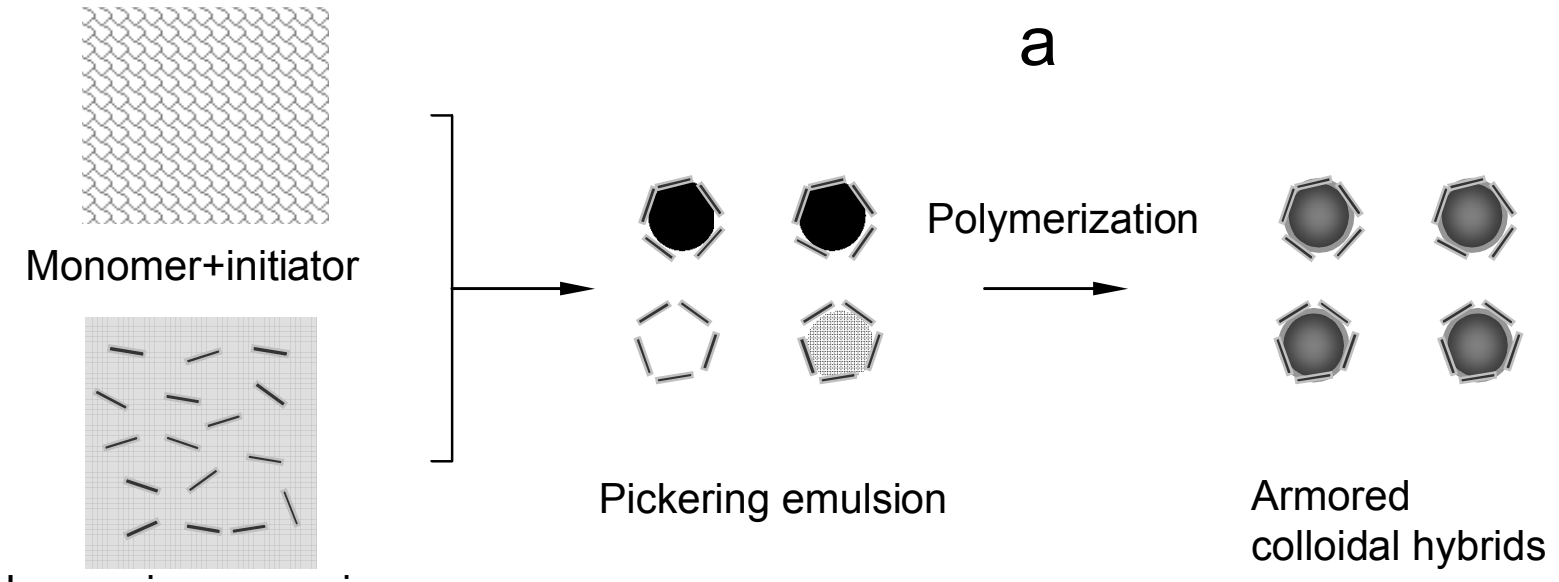

Inorganic suspension

Armored
colloidal hybrids 


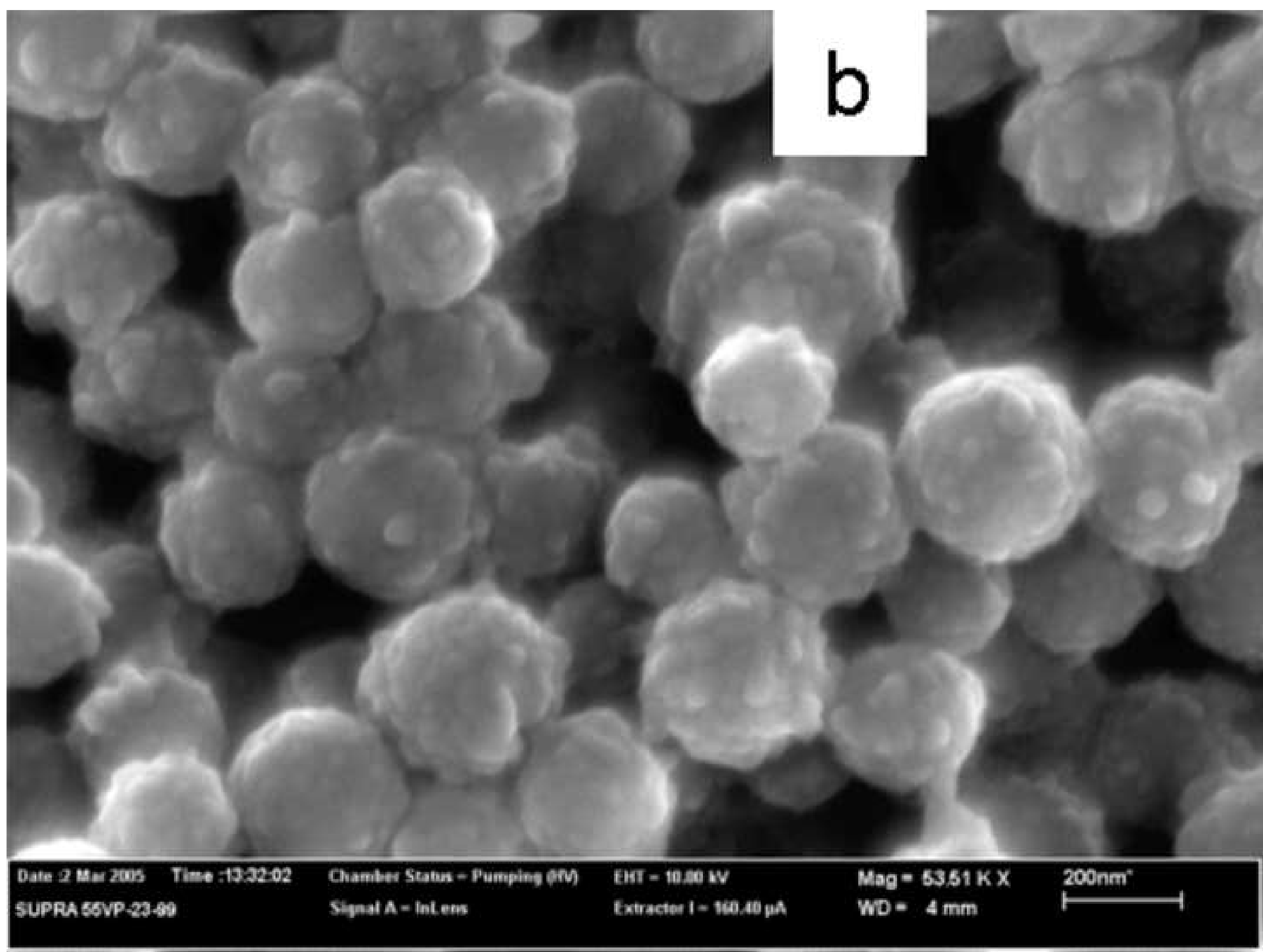


Click here to download high resolution image

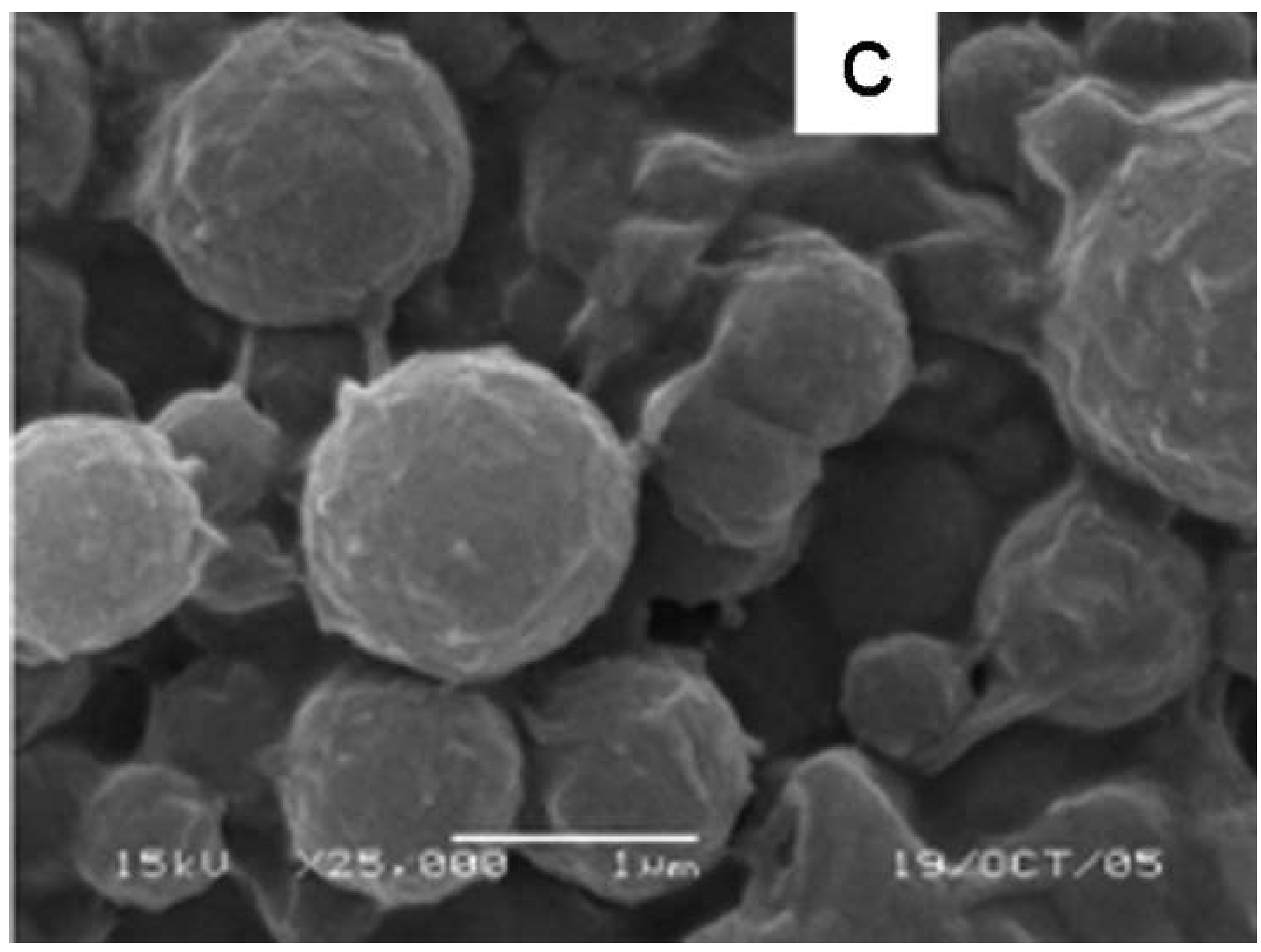




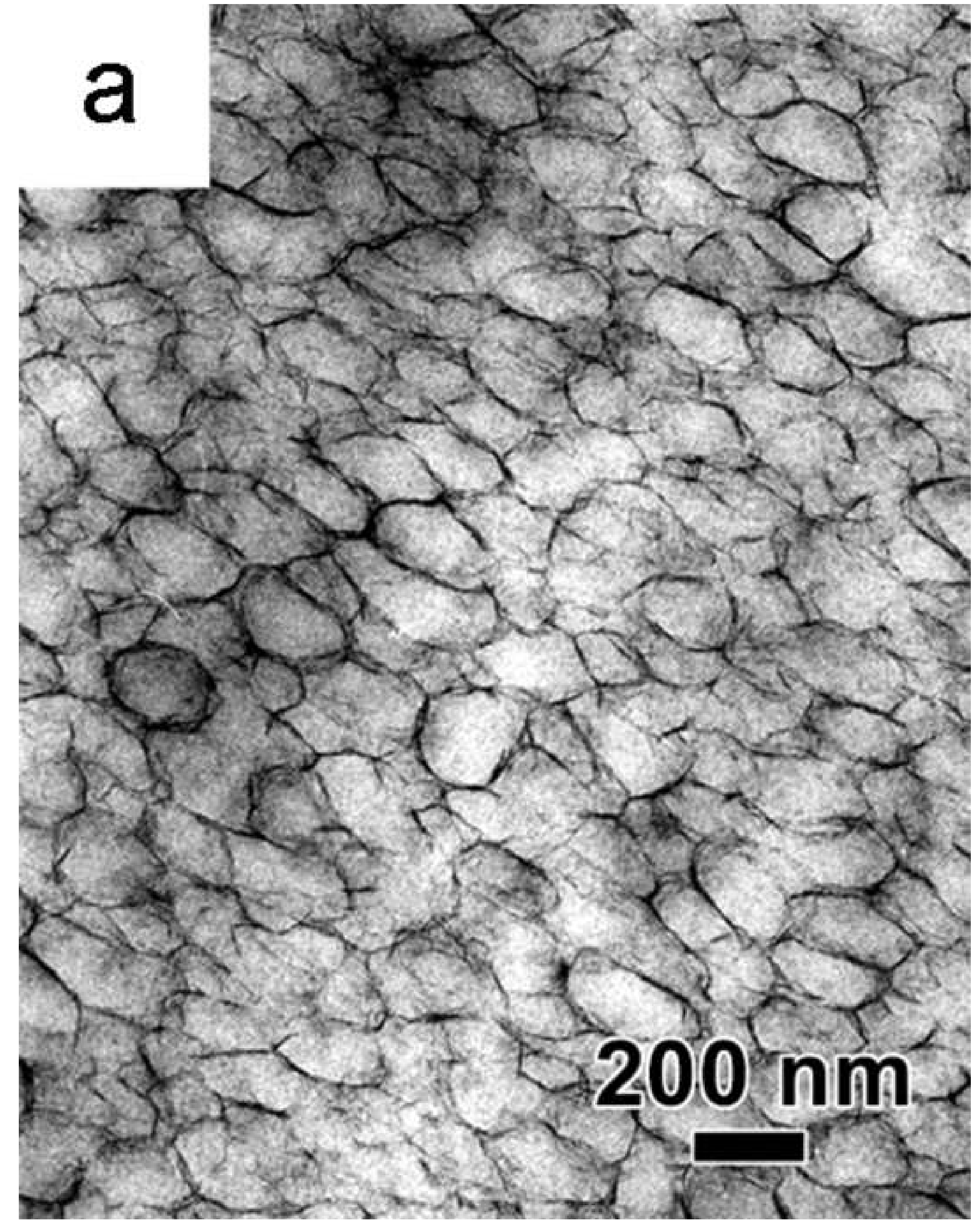




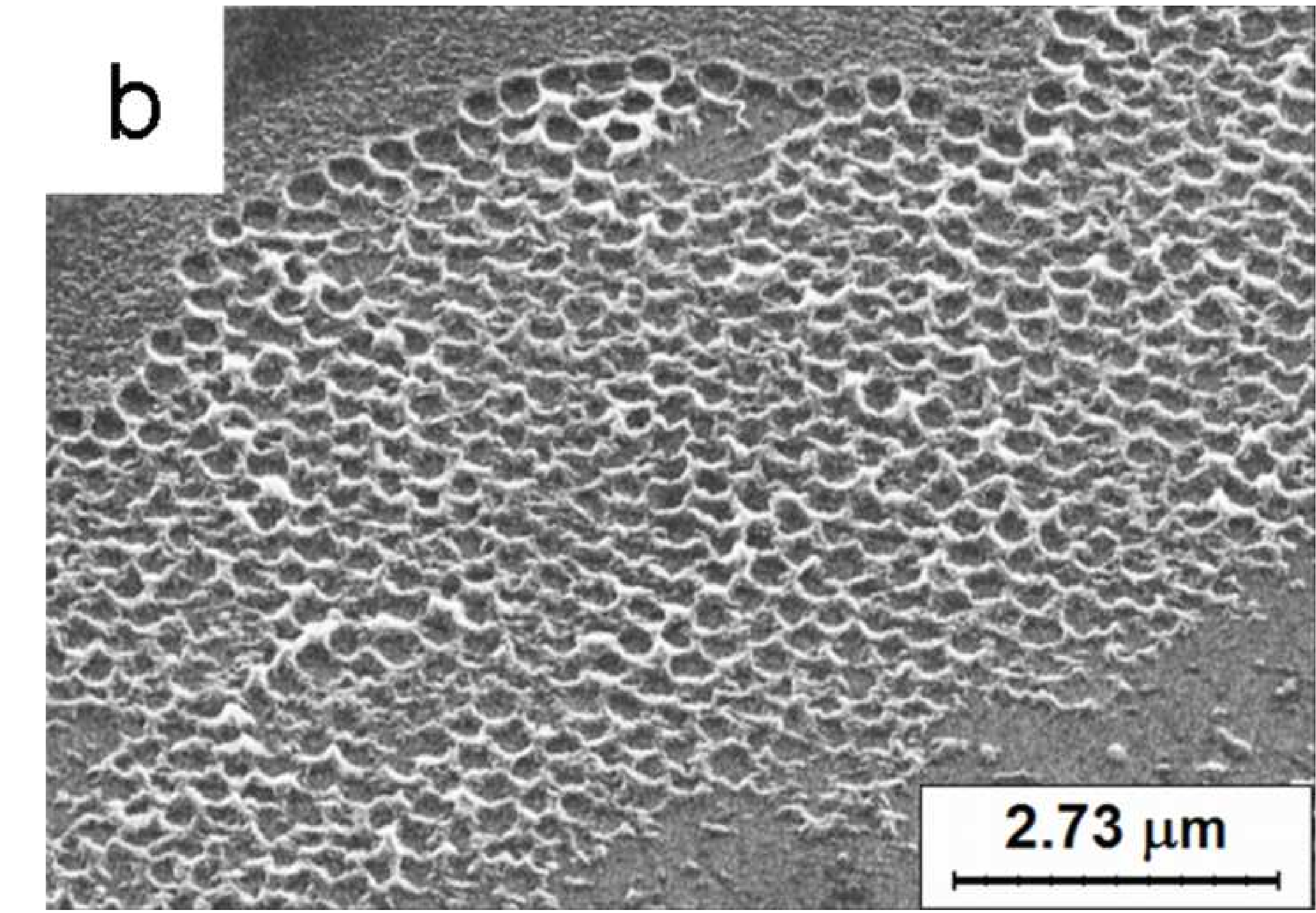
. .

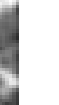

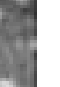

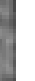



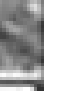



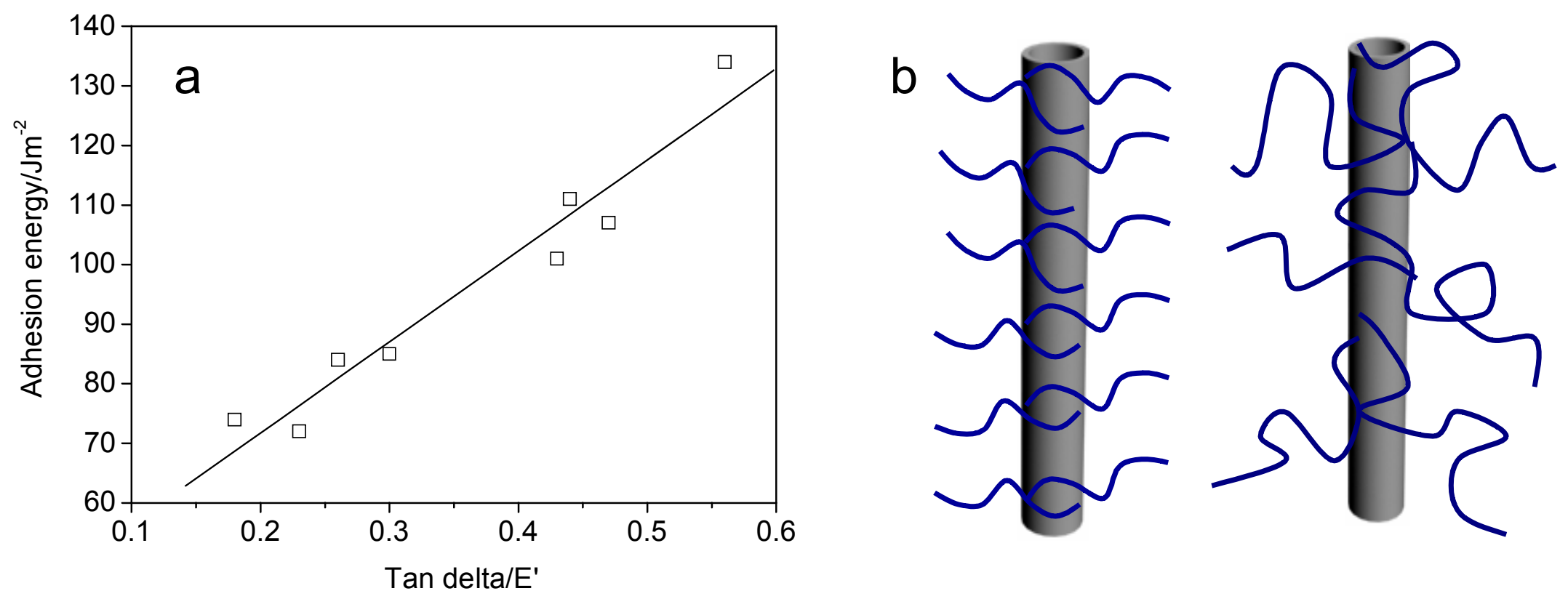